\title{
The Problem of Parmenides: An Analysis of the Dialogue with a View Towards its Ethical Implications
}

by

\author{
Iain Laidley
}

A thesis submitted to the Faculty of Graduate and Postdoctoral Affairs in partial fulfillment of the requirements for the degree of

Master of Arts

in

Philosophy

Carleton University

Ottawa, Ontario

(C) 2012, Iain Laidley 
Library and Archives

Canada

Published Heritage

Branch

395 Wellington Street

Ottawa ON K1A ON4

Canada
Bibliothèque et

Archives Canada

Direction du

Patrimoine de l'édition

395 , rue Wellington

Ottawa ON K1A ON4

Canada
Your file Votre référence

ISBN: 978-0-494-91601-8

Our file Notre référence

ISBN: $978-0-494-91601-8$
NOTICE:

The author has granted a nonexclusive license allowing Library and Archives Canada to reproduce, publish, archive, preserve, conserve, communicate to the public by telecommunication or on the Internet, loan, distrbute and sell theses worldwide, for commercial or noncommercial purposes, in microform, paper, electronic and/or any other formats.

The author retains copyright ownership and moral rights in this thesis. Neither the thesis nor substantial extracts from it may be printed or otherwise reproduced without the author's permission.
AVIS:

L'auteur a accordé une licence non exclusive permettant à la Bibliothèque et Archives Canada de reproduire, publier, archiver, sauvegarder, conserver, transmettre au public par télécommunication ou par l'Internet, prêter, distribuer et vendre des thèses partout dans le monde, à des fins commerciales ou autres, sur support microforme, papier, électronique et/ou autres formats.

L'auteur conserve la propriété du droit d'auteur et des droits moraux qui protege cette thèse. $\mathrm{Ni}$ la thèse ni des extraits substantiels de celle-ci ne doivent être imprimés ou autrement reproduits sans son autorisation.
In compliance with the Canadian Privacy Act some supporting forms may have been removed from this thesis.

While these forms may be included in the document page count, their removal does not represent any loss of content from the thesis.
Conformément à la loi canadienne sur la protection de la vie privée, quelques formulaires secondaires ont été enlevés de cette thèse.

Bien que ces formulaires aient inclus dans la pagination, il n'y aura aucun contenu manquant. 
The Problem of Parmenides

Iain Laidley

\begin{abstract}
In this thesis, I argue for three primary claims: (1) that the two major contemporary readings of Parmenides are not in conflict and can be reconciled; (2) that even a combination of these two readings misses the importance of the method of hypothesis in Parmenides; (3) that paying close attention to the method of hypothesis unearths ethical content in Parmenides. In order to ground these claims, I first develop a heuristic with which to analyze Plato's Parmenides. This heuristic breaks down the dialogue into a number of questions to be answered about the text; I argue that the best reading of Parmenides is the one that most effectively and thoroughly addresses each question. From there, by applying this heuristic to the accounts of Constance Meinwald and Mary Louise Gill, I both show that they are compatible and that they do not place sufficient importance on the method of hypothesis.
\end{abstract}


The Problem of Parmenides

Iain Laidley

\section{Acknowledgments}

This thesis would not have been possible without the consistent support of a number of people. First and foremost, I would like to thank Professor Annie Larivée, whose close attention to detail-stylistic and philosophic-improved this thesis immeasurably. A number of the objections to which I respond are hers, and the vast majority of them are novel ones that I had not encountered in the literature. I would also like to thank Brittany Lattanzio, both for suffering through large portions of this work in its unedited formwhether in text or out loud-and for introducing me to the debate around the method of hypothesis, and talking out its implications for Parmenides with me. This second debt is clearly an enormous one; without her input, this thesis would be orders of magnitude less interesting. Also vital for the present work was the input of Professor David Matheson, whose unflagging enthusiasm for this project was much appreciated, and whose

comments on the initial draft that inspired this work were thorough and thoughtful. Finally, I would like to thank Professor Brook Pearson for introducing me to Plato, and whose love for the dialogues inspired my own. Thank you to all of you for your enormous contributions to this project.

I would also like to thank those that helped me work through various sections of this thesis in its draft form, including Jonathan Courtney, Josephine Nielsen, and Justine McLeod, as well as Mary Renaud and Matthew Scarfone for listening to me ramble about Parmenides, and telling me if I made even a little sense. Hopefully, I did and do.

In closing, thank you to my family for your support and love. 
The Problem of Parmenides

Iain Laidley

Table of Contents

Abstract ii

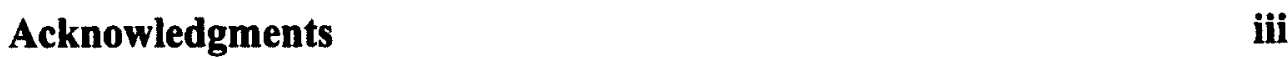

Chapter 1: Establishing a Heuristic

1.1: Introductory Remarks 1

1.2: Methodology 3

1.3: Summary of Parmenides: Zeno, Socrates, and Parmenides on the Forms 6

1.4: Parmenides' Method and Deductions 12

1.5: Parmenides' Features of Interpretive Significance 22

1.6: Structural Features of Parmenides 23

1.7: Logical and Argumentative Features of Parmenides 29

1.8: Features External to Parmenides 34

Chapter 2: Meinwald and Gill: Applying the Heuristic

2.1: Methodological Remarks 38

2.2: The Gymnastic Approach to Parmenides 39

2.3: Objections to Meinwald 61

2.4: Gill, Rickless, and the Metaphysicalist Reading
of Parmenides

2.5: Objections to the Metaphysicalist Account 77

2.6: Taking Stock 81

Chapter 3: The Method of Hypothesis in Parmenides

3.1: Outline of Chapter Three $\quad 90$

3.2: The Method of Hypothesis in Phaedo, Meno and Parmenides $\quad 92$

3.3: Hypothesis, Formalized 96

3.4: The One as Arche or Unhypothetical Starting Point $\quad 102$

3.5: Reflecting on the Strength of the Revised Meinwald-Gill Theory

3.6: Concluding Remarks: the Young Socrates and an Art [techne] of Life 112 
The Problem of Parmenides

\section{1: Introductory Remarks}

Constance Meinwald opened her book on Plato's Parmenides in 1991 with the note that 'Plato's Parmenides today finds itself in a strange position: it is clearly an important work, but its import remains remarkably unclear' (Meinwald 1991: 3). Over twenty years later, this still seems to be true. The significance of Parmenides has variously been taken to be the communication of a certain type of predication that is meant to structure mental exercises (Meinwald), that a careful study of the contradictions in the second part of the dialogue will solve a number of problems about the forms (Gill, Rickless), a study in the ambiguity of the verb 'to be' (Cornford), a reductio ad absurdum of Parmenides' philosophy (Graeser), a study of the ontological ideas of previous thinkers (Sayre), and the culmination of all of Platonic philosophy (Proclus). ${ }^{1}$ The secondary literature here is as opaque as the Parmenides itself, which is made up of two parts with no obvious connection, the second of which is full of antinomies or apparent contradictions, while at the same time having features that seem to suggest that Parmenides is of enormous importance: Socrates' youth, Parmenides' objections to what seems to be the standard account of the forms, ${ }^{2}$ and so on. It is difficult to know, then, what to make of the dialogue. In this thesis, I am going to propose not just an answer to this problem, but also a formal methodology with which to approach it.

The argument that I will be advancing here will seek to bring Parmenides into conversation with Plato's other dialogues. In the first chapter, I will identify what I call the features of interpretive significance for Parmenides. These are the elements of the

\footnotetext{
${ }^{1}$ Those listed here are only the interpretations that have had a lasting impact on English-language Platonic scholarship. There are an uncountable number more of those that have been less influential.

${ }^{2}$ This curiosity is augmented by the similarity between some of Parmenides' objections to Socrates and Aristotle's objections to Plato in Metaphysics.
} 
text that any interpreter must explain in order to give a satisfying account, including the content of the arguments, Parmenides' methodological remarks, and the characters present, among other facets of the text. In addition, this analysis will include extradialogue elements, like explaining remarks in Aristotle, or links with other parts of Plato's work. Doing this will make possible the project of Chapter Two, in which I will lay out the two dominant positions in modern scholarship, by providing us with a way to contrast interpreters' answers to particular questions about the text. Taking those proposed readings by the dominant voices in the debate around Parmenides, Constance Meinwald (1991, 2005, forthcoming) and M. L. Gill (1996, forthcoming), I will try to identify the precise points on which they seem to disagree, and show that their interpretations are not just compatible, but are in fact complementary to each other. That is to say, the contradictions between their positions are in most cases merely apparent. However, spelling out those features that require explanation will have the further benefit of showing the places where both interpretations fall short. In Chapter Three, I will improve the combined Meinwald-Gill thesis by adding to it a focus on the method of hypothesis in Parmenides that they both overlook and defend it from a number of objections. This focus will allow me, in the conclusion of the third chapter, to suggest that there is broader ethical and epistemological relevance to Parmenides. Thus, we will be exploring three related claims:

(1) Meinwald's and Gill's readings of Parmenides are not incompatible; in fact, with a close reading of each of them, they can be combined productively.

(2) Neither Meinwald's nor Gill's reading pays close enough attention to Parmenides' methodological remarks. Specifically, they make no mention of his 
claim that Socrates should 'hypothesize'. With reference to Meno, Phaedo, and Republic, as well as the literature around the method of hypothesis in Plato, I will show that we can greatly strengthen a reading of Parmenides by noting the specific implications of this part of Parmenides' instructions.

(3) Parmenides has useful data not just for readers interested in Plato's methods, as (2) would suggest, but also for those arguing that Plato has a eudaimonistic ethics. It is my hope that, by making it clear that much of the disagreement over Parmenides is apparent as opposed to actual, I can in some small way help to broaden the scope of the scholarly conversation about Parmenides. Though it is currently used as evidence for accounts of Plato's metaphysics, or as a source for the roots of Neoplatonism, I hope to be able to justify by the end of Chapter Three my suggestion that Parmenides' importance extends well into the realm of the ethical.

\section{2: Methodology}

It seems that the strongest possible reading of any particular text is that which explains the individual elements of that text most persuasively. Consider, for example, two hypothetical readings of Parmenides. The first reading adequately explains two elements-character choice and the relationship between the two major parts of the dialogue-and does not mention much else, whereas the second one explains only one completely different element, for example the temporal framing of the introduction. By this principle, the stronger reading is the first one, as it has more explanatory power as defined above. Identifying these individual elements of the text that require explanation has a further beneficial side-effect; we can more easily identify the places where there is only apparent disagreement between interpretations as opposed to actual disagreement if 
we make explicit what each interpreter is trying to explain. That is, though particular interpretations may fundamentally disagree on particular elements that they both address, elements that are addressed only by one of the interpretations may be able to be integrated into the other. This makes arbitration between secondary sources much more consistent and thorough. Thus, by compiling each textual detail of Parmenides that requires explanation, and employing this compilation as a heuristic device, it seems as if we can more easily engage with the dominant interpretations of Parmenides for two reasons. First, the evidence that each reading uses is catalogued, such that it is easy to see where each interpretation is strong or weak; second, the two interpretations can be set beside each other, and we can see where they are actually in conflict. As a result, we should be able to engage with Plato scholarship as a whole from the perspective of Parmenides.

There are two types of data then that need to be collected for the project. The first type is those elements of Parmenides that require interpretation. Sometimes, these elements of the text are already at the centre of prominent arguments about Parmenides, and thus any interpretation found in the secondary literature is likely to make arguments based on them. For example, there are two aspects of Parmenides that are considered generally to be the central questions of the dialogue: (a) what the connection is between the elenchus between Parmenides and Socrates in the first part of the dialogue, and Parmenides' lengthy discourse in the second part of the dialogue, and (b) whether the arguments in Parmenides' exercise in the latter section of Parmenides are in contradiction with each other, and if they are, whether that is a deliberate decision on Plato's part. Both Meinwald's and Gill's interpretations give answers to these questions that represent the 
core of their interpretations, and any interpreter must do so. There are, however, parts of the text that are less central to the current conversation that require some attention. For example, as I argued briefly above, neither Meinwald nor Gill spill much ink over the notion of hypothesis in Parmenides' method. We ought to pay attention then not solely to those parts of the text that have engendered the most debate, but also certain aspects that seem relatively uncontroversial.

Further, there are two more sources of relevant data for a reading of Parmenides, external to any modern commentary or the dialogue itself. The first is inter-dialogue data. As Charles Kahn (1996) has noted, one of the central problems of Plato scholarship is trying to understand the dialogues not as atomic texts, but as connected with the other dialogues in some important philosophical way (Kahn 1996: 37). There are clear links between many of Plato's works. Take, for example, Socrates' cutting short the conversation in Theaetetus in order to 'go to the King's Porch to meet the indictment Meletus has brought against [him]' (210d), where the conversation with Euthyphro begins. Though perhaps this is not central to readings of Theaetetus and Euthyphro, it seems that it requires explanation. In the same way, clear links between Parmenides and Republic, Phaedo, Meno, among others, beg for interpretation. ${ }^{3}$ Finally, there is material written by Plato's near-contemporaries. Though any suggestion of a link between Parmenides and Aristotle or Speusippus, for example, is likely to be speculative, if a compelling case can be made that a particular understanding of Parmenides can help to

\footnotetext{
${ }^{3}$ There is a fair amount of literature on the link between Parmenides and Sophist and Statesman, as well as Theaetetus. For the first two, cf. Turnbull (1998); for all three, $c f$. Meinwald (1991, forthcoming) and Gill (1996, forthcoming).
} 
explain parts of Speusippus' philosophy, ${ }^{4}$ then this may well count in favour of that reading, though it is hardly decisive. Thus, we must pay close attention not only to Parmenides itself, but further to Plato's other dialogues and the writings of Aristotle and Speusippus with Parmenides in mind.

After setting up the heuristic framework, I will argue along with Meinwald and Gill, among others, that key elements of Parmenides are not well examined and are poorly understood. Though the accounts that they give can be made to strengthen each other, they both miss a key part of Parmenides' methodological remarks: his assertion that Socrates should 'hypothesize'. If we focus on the implications of this instruction, especially in contrast with passages in Phaedo, Meno, and Republic, we are better able to explain parts of Parmenides that have not adequately been addressed by interpreters. This includes the relationship between the first and second parts of the dialogue, especially the question of why standard elenchus is employed in one but not the other, the presence of Glaucon, Adeimantus, and Parmenides, and the choice of subject for the deductions of the second part. By making explicit the importance of Parmenides' instruction to Socrates that he hypothesize, we can make compelling arguments for both readings of Parmenides that take the central point to be a metaphysical one-a metaphysicalist account-and for those readings that argue instead that Parmenides has primarily a linguistic or logical upshot-the 'gymnastic' account. This is what I take to be the primary distinction between my current work and that that already exists.

\section{3: Summary of Parmenides: Zeno, Socrates, and Parmenides on the Forms}

\footnotetext{
${ }^{4}$ J. M. Dillon (2005) makes this very claim, arguing that the only way to see how Speusippus' philosophy bears much of a relationship to Plato's is to posit him having a particular reading of Parmenides.
} 
In order to be able to engage with Parmenides in this way, it is necessary first to give a summary of the dialogue. The following will be of unusual length for a summary, but this is for good reason. Parmenides is not generally widely read, and when it is, the first response is more often than not puzzlement. As a result, by summarizing the dialogue in distinct sections, it is easier to approach it as a whole when the interpretive exercise begins. Further, this helps to contextualize the textual elements that are the centre of my approach by giving an accurate account of the arguments in which they are involved.

Parmenides is generally understood to have two major parts that are introduced by a unique preface. The narrator, Cephalus, is relating his trip to Athens to an unknown audience that never interjects (126a). He crosses the sea from Clazomenae with the express purpose to seek out Glaucon and Adeimantus-Plato's brothers-and ask them to take him to Antiphon, so that the latter can rehearse to him Socrates' conversation with Parmenides from memory (126b). Glaucon and Adeimantus agree, and Antiphon rehearses the conversation that he himself heard Pythodorus recite from memory long before. Socrates is long dead by this point; the events of Parmenides are meant to have taken place at least fifty years prior to Cephalus' visit. The first major part of Antiphon's story is concerned primarily with the examination of Socrates by Parmenides. In it, Socrates, at the age of nineteen or so, has a discussion with Zeno about one of the latter's arguments. Zeno has suggested, prior to the initiation of the dialogue, that by deriving the consequences of the statement that 'the many are" we become mired in a hopeless contradiction: it seems that if the many are, we are forced to assert numerous

\footnotetext{
${ }^{5}$ Or, that multiplicity exists.
} 
contradictory positions (127e). This does not impress Socrates, and he claims that showing that particulars have contradictory properties is neither difficult nor philosophically interesting. Instead, if one could show 'that the likes themselves come to be unlike or the unlikes like' (129a) he would 'marvel'. That is to say, Socrates suggests that Zeno's paradoxes are not really a problem because it seems that they do not apply to the forms.

Following this exchange, the main event of the first part of Parmenides is Parmenides' cross-examination of Socrates. After Socrates articulates a rudimentary notion of the forms in his engagement with Zeno, Parmenides begins to question him in much the same manner that Socrates would question one of the interlocutors of the 'Socratic' dialogues. Specifically, Parmenides asks for the details of Socrates' view and, after eliciting these details, gives a number of objections to the account. ${ }^{6}$ The first question Parmenides asks seeks to clarify two things: (a) what the relationship between forms, and between forms and sensibles are and (b) what types of entities have their own forms. Socrates confirms that forms are separate from each other and separate from the particulars that partake in them. That is to say, in a phrase that recurs in Parmenides and in other dialogues, each form is 'itself by itself', or $a u[\tau B k a \theta$ ' $\alpha u[\tau B$ Socrates' claim that the forms exist themselves by themselves is key for the objections Parmenides later gives. Next, Socrates replies when questioned that there are definitely forms for what is 'just, and beautiful, and good' (130b), but is unsure about human beings, and is certain there are no forms of 'mud and dirt, or anything else totally undignified and worthless' (130d). Parmenides then asks about the mechanics of participation, and particular properties of

\footnotetext{
${ }^{6}$ For a detailed analysis of these objections, cf. Allen (1997) pp. 104-203. For obvious reasons, I cannot go into the same level of detail that he does: I cannot spare a hundred pages for my summary!
} 
forms. His first objection is based on a dilemma he sets up between particulars participating in the whole of a form or a part of a form. That is to say, Parmenides wonders whether a just particular partakes in the whole of Justice, or a part of Justice. Each horn of the dilemma is problematic, and this represents a major problem for Socrates. If a just particular gets the whole of the Just, and it is placed next to another just particular, then it seems as if the whole of the Just is in two places at once, which is impossible (131a). On the other hand, if the just particular participates only in a part of the Just, then forms are divisible, and thus not unified wholes (Meinwald 1991: 158). If the forms are not unified wholes, then Socrates is exposed to another type of objection. If, for example, both Socrates and Parmenides have a part of the Small, " $[\mathrm{t}] \mathrm{he}$ small will be larger than that part of it, since the part is a part of it: so the small itself will be larger!' (131e $)^{7}$. Thus, as Allen calls it, there seems to be a dilemma of participation; no matter which 'way' the particulars participate in the forms, there seems to be an unsavoury consequence.

If we grant those premises from which we derive the first dilemma-and Socrates does, even if that may be unjustified-there is a second dilemma. If the Large itself is large, and particulars are large, then 'there seems to be some one character' (132a) by which Largeness and large sensibles are similar. Parmenides claims that if the Large itself and large things are made large by the same entity, there must exist another form, a Largeness 2 , to explain the likeness between large particulars and Largeness (132b). ${ }^{8}$ To try to defend himself from this problem, he argues that each form or eîंos could be a

\footnotetext{
${ }^{7}$ This objection, to be made valid, rests on the assumption that the form of a particular property must embody that property to the greatest possible degree, what Meinwald calls 'superexemplification'. This will be important in chapter two.

${ }^{8}$ This has the general structure of what we have come to call, following Aristotle, the Third Man argument.
} 
'thought...[that] properly occurs only in minds' (ibid). Socrates, though, is committed to two claims: (1) that a thought cannot be of nothing, and it must be of 'something that is' (132c), and (2) given these thoughts are functioning as sources of particular characters, that each idea must be of one single character. This implies, however, that all things are ultimately composed of thoughts 'and all things think' (132c), which is an unacceptable consequence. Again, Socrates is thwarted. Socrates next tries to conceptualize the forms as 'patterns set in nature' (132d)-blueprints upon which particulars are modeled.' However, this leads to a familiar problem. Parmenides argues that if something resembles a form, which it must if it is modeled upon it, then that form also resembles the particular. Thus, just as a house resembles the blueprint, the blueprint resembles the house. However, in order for the blueprint and the house to be similar, there needs to be, in Parmenides' estimation, yet a third entity upon which the blueprint and the house are modeled, as is implied by the 'One over Many' principle. ${ }^{10}$ As a result, 'nothing can be like the form, nor can the form be like anything else. Otherwise, alongside the form another form will always make its appearance, and if that form is like anything, yet another' (132e). We seem to have a regress of resemblance if we take Socrates' paradigm theory and Parmenides' objections to it seriously.

Finally, Parmenides articulates what he takes to be the most problematic objection for Socrates' account (133b). If forms are themselves by themselves, then they are not in us, and forms of relational properties have their actual relations with other forms, not with particulars. That is to say, the Small is said to be small in relation to the Large, not

\footnotetext{
${ }^{9}$ This is the major source for Sayre's paradigm theory in Plato's Late Ontology (1983).

${ }^{10}$ One over Many is the assumption that, in Rickless' (2007) terms, for any property $F$ and those entities that partake in that property, there is a single form of $F$-ness in which all entities that have that property must also partake.
} 
in relation to an elephant or the Empire State Building. Similarly, we say an elephant is large in relation to a turnip, not in relation to the Small itself. This has problematic consequences. Take, for example, the form of Chemistry. Chemistry itself knows the form of Hydrogen; that is to say, Chemistry itself is knowledge of Hydrogen itself, it is not knowledge of actual hydrogen. Thus, it seems that Chemistry knows nothing of actual hydrogen, and though we may, being in the world, know things about actual hydrogen, know nothing of the Hydrogen itself. ${ }^{11}$ It is unclear, then, how the forms bear any relationship to the world of sensible objects in which human beings exist. The Elephant is afraid of the Mouse, but not of the particular mice in the world, and any particular elephant is not afraid of the Mouse. If this is the case, and human beings are part of the world of sensible objects, it seems we cannot know the forms or anything about them, and nor can the form of Knowledge know us. Given that Socrates claims to use these same forms about which he can apparently know nothing as part of an account, it seems that he has a problem; how is he meant to give an account of entities to which he has no access? This is Parmenides' final objection: it seems that Socrates' forms have no way of interacting with the sensible world, thus making them useless as explanatory devices.

Parmenides, after providing this series of objections to Socrates' theory, is not willing to reject it; indeed, though he is skeptical of Socrates' account, he suggests that the forms are absolutely indispensible. That is to say, while it may be the case that the forms as Socrates has presented them are incoherent-or at the very least unknowableentities very much like them must exist in order to anchor predicates ontologically.

\footnotetext{
"This example is adopted from (Meinwald 1991: 18), though modified to be slightly more intuitive. The initial reaction to the notion of Chemistry 'knowing' something - as if that seems to be assigning properties to Chemistry - is indeed problematic. This will be important in chapter two, but for now it is worth granting that that proposition makes sense in some way.
} 
Parmenides claims that if someone 'doesn't allow that for each thing there is a character that is always the same' then 'he will destroy the power of dialectic' (135c). Note that the word being translated here as 'dialectic' is $\delta 1 \alpha \lambda \varepsilon^{\prime} \gamma \varepsilon \sigma \theta \alpha 1$, which means not only technical philosophical discourse, but also standard conversation. Given that conversation and dialectic do seem to be possible, based on the fact that Socrates and Parmenides are at the time of this statement participating in it, it seems as if forms must, in Parmenides' view, exist in some way. As Parmenides has no interest in actually abandoning the forms, he suggests to Socrates that the problem is not the claim that there are forms, but Socrates' account of that claim. He claims that Socrates has been trying to theorize about the forms 'before [he has] been properly trained' (135c-d). To this end, Parmenides proceeds to outline a method of training that Socrates should pursue in order to be able to reason properly about properties and abstract objects in the future, an example of which constitutes the second part of the dialogue.

\section{4: Parmenides' Method and Deductions}

First, Parmenides commends Socrates on forcing Zeno not to discuss particulars, but 'those things that one might above all grasp by means of reason and might think to be forms' (135e): abstract objects as opposed to sensible ones. This is unsurprising, given that Parmenides is proposing this training in order to improve Socrates' account of the forms. Second, and more controversially, some commentators have placed a great deal of emphasis on Parmenides' claim that the training Socrates is meant to undergo is in the manner that '[Socrates] heard from Zeno' (ibid). ${ }^{12}$ They take from this passage that Socrates should then focus on trying to develop paradoxes of the type for which Zeno is

\footnotetext{
${ }^{12}$ Cf. Gill (1996), Rickless (2007).
} 
famous: his hypotheses should end in both $p$ and not-p, thus suggesting that the initial hypothesis is false. It is clear how reading this line as a key part of Parmenides' instructions could modify an account of the passages that follow. Particularly, we will find on examination of the deductions of the second part of the dialogue that if we put much emphasis on this comment, we will find it unsurprising that pairs of deductions do seem to contradict each other. It is, then, worth noting that it is possible that Socrates is meant to develop Zeno-like paradoxes, though this is a controversial point; if we hold that the arguments of the second part of the dialogue are not only valid but also at least intended to be sound, this obviously is in direct conflict with any instruction to generate contradictions. Third, Parmenides suggests that Socrates must hypothesize not only 'if each thing is, and examine the consequences of that hypothesis; [he] must also hypothesize, if that same thing is not' (136a). That is, in generating his exercises, Socrates must assume not just his hypotheses, but also their contraries. This is the only way that he can properly flesh out his account. Finally, using as an example the hypothesis that 'the many are' Parmenides claims that Socrates must derive 'the consequences...both for the many themselves in relation to themselves and in relation to the one, and for the one in relation to itself and in relation to the many' (ibid). He must perform the same exercise for the negative hypothesis, 'if the many are not'. Given the hypothesis 'Justice is', Socrates must derive the consequences for Justice in relation to itself, Justice in relation to injustice, injustice in relation to itself, and injustice in relation to Justice, and the repeat the process for 'Justice is not'. Drawn together, then, in order to 'achieve a full view of the truth' (136c), or 'hit upon truth and gain insight' (136e), Socrates must perform a complex set of exercises. He must (a) hypothesize not just his 
positive claim, but also its negation, (b) hypothesize about form-like entities as opposed to particulars, (c) derive the consequences of his hypotheses in relation to their subjects and in relation to their subject's others, and (d) possibly try to derive Zeno-like paradoxes. Understandably, Socrates requests that an example is given; in the abstract, it is not at all clear what these instructions mean. Parmenides reluctantly agrees to demonstrate, using his own hypothesis as an example: 'the one is' (137b). The bulk of Parmenides is taken up by Parmenides' discussion of this example with Aristoteles. The standard account would suggest that there are eight sets of deductions, with an appendix to the first two, bringing us to a total of nine distinct sections of argument, which range in length from twelve Stephanus pages down to less than one. I will not be reviewing each argumentative step in detail, as it is simply not possible to do each of them justice in limited space. ${ }^{13}$ I will instead focus on making clear the general geography of the section, and make note of those parts of the arguments that are most often cited in discussion around Parmenides. In particular, I will be noting: (a) key conclusions of deductions that will require some explanation, (b) contradictions between deductive sets, (c) contradictions internal to a single deductive set, and (d) the general shape of the argument of the eight sets.

The first and second deductions are generally considered as a pair for a number of reasons. First, each is concerned with deriving the consequences of Parmenides' positive hypothesis: 'it is one' (137c). Second, Parmenides derives from the first deductive set

\footnotetext{
${ }^{13} \mathrm{Cf}$. Rickless (2007) for a detailed and charitable analysis of every step of each argument, including a catalogue of the assumptions that must be made explicit in order for them to make sense. He has made the case that if reconstructed charitably, the vast majority of the arguments of the second part are valid ones, and that those that are not were likely not to have been intentionally bad. This is by far the most detailed analysis of the arguments in existence, and I am inclined to agree with Rickless' conclusion.
} 
that the one cannot be named or spoken of, no account can be given of it, and it cannot exist (141e); in the second set, he derives the contrary, claiming that not only must the one exist, but it can be an object of knowledge, and an account can be given of it (155d). ${ }^{14}$ Given that these two deductions start from the same point, it is worth noting how precisely they seem to get to opposite places. The first argumentative move of the first deduction is that by definition the one cannot be many. If the one cannot be many in any way, then it must not partake in any other form. If it does not partake in any other form, it cannot partake in the form of being: as a result, it cannot exist. From the fact that the one cannot exist, Parmenides derives the conclusion that we cannot speak of it, and we cannot give an account of it. Aristoteles, who Parmenides has chosen as an interlocutor, expresses some skepticism that this is the case-it certainly seems that Parmenides has been speaking about the one for some time, and it is unlikely that the one cannot be spoken about if this is the case. Thus, in the second deduction, Parmenides makes as his first move that if one is, then the one must exist; it is unclear to him how an entity could have any properties without existing. However, this too leads Parmenides into some trouble. If it participates in being, then Parmenides claims that the one must have as one part being and as the other part oneness. However, as each of these parts both exist and are one, then each of those parts must also have parts that can be divided into being and oneness. As a result, Parmenides claims that the one can be divided indefinitely into one and being. Thus the one is not just many: it is infinitely many (143a). Though an

\footnotetext{
${ }^{14}$ This bears some strong similarity, as John Palmer (1999) has convincingly argued, to Gorgias' On NotBeing. I am not going to discuss this thesis in detail, but it is worth mentioning that it has been put to some (limited) use. The best account that has been made of Gorgias' inclusion has been by Sandra Peterson (2003), who argues that this suggests that continued rounds of this exercise could take other historical figures' theses as a starting point for their deductions.
} 
account can in this case be given of the one, it seems unpalatable to suggest that the one is in absolutely no way one, and is instead many.

There are a few things to keep in mind about the first pair of deductions, then. First, they seem to derive entirely opposite conclusions; second, it looks as if we cannot accept the content of either deduction without further nuance, as either we hold that the one is one but does not exist, or hold that the one exists but is not one. Both of Parmenides' deductive sets so far, then, have unpalatable conclusions, and it is unclear how we can hold that the one exists.

The next set of arguments is generally considered to be a short appendix to these first two, and attempts to introduce the notion of time to solve the problem of how it is that the one can embody contrary properties, essentially by suggesting that it can do so at different times. That is, " $[\mathrm{i}] \mathrm{f}$ the one is as we have described it—being both one and many and neither one nor many, and partaking of time-must it not, because it is one, sometimes partake of being, and in turn because it is not, sometimes not partake in being?' (155e). This has potential to solve the problem of the relationship between the two deductions. If the one is at time $t_{1}$, and is not at time $t_{2}$, then there is nothing incoherent about saying the one both partakes and does not partake in being. Further, time can help us to resolve one of the problems in the first deduction. Parmenides claims that an event that occurs in an 'instant' takes place 'in no time at all' (156d); that is, some changes can happen outside of time. As the one, if it is to change from partaking of being to not partaking of being cannot embody both of these properties at the same time, it must embody neither of them in an instant; the one can go from being to not being only by embodying neither of these properties for an intermediary instant. 
The introduction of time can thus provide potential solutions for the apparent contradiction between the first and second deductions. There is some controversy as to whether this attempt is successful. Gill argues that the appendix fails, and only reinforces the conclusion of the first hypothesis, that the one is not (Gill forthcoming: 12); on the other hand, Meinwald argues that the time indices reveal that there was no contradiction after all (Meinwald forthcoming: 21 n.25). Thus, Parmenides both acknowledges and tries to resolve the contradiction between the first and the second deductions; whether or not this attempt is successful is up for some discussion.

The third and fourth sets deductions are, as forecasted by the methodological remarks, considerations of the consequences for the others-those things that are not the one-in relation to themselves and the others in relation to the one. Just as the first two deductions seem to derive conclusions about the properties of the one that seem to be contraries, so the third and fourth deductions do the same for the properties of the others. In the third, we find the properties of the others in relation to the one. The first inferential move of the deduction is that the others must not be the one, but must in some way partake in the one, because to be other than the one they must have parts; if they did not have parts, they would be one. Parmenides deduces that if the one is, the others must be both limited and unlimited (158d). The others are unlimited because if parts are parts of a whole, and each part partakes in one, then in order not to be identical with the one, each part must itself be many, and thus have parts as well. As a result, we have a regress of parts. In contrast, they are limited because the wholes are limited by their parts, and the parts have limits in relation to each other. From this, it follows that the others are like and unlike each other and themselves (158e), because they are like insofar as they share the 
property of being limited or the property of being unlimited, and unlike insofar as some of them are limited and some of them are unlimited. Parmenides then claims that from this, we can derive that they are both in motion and at rest and 'have all of the opposite properties' (159b). It seems that the others must embody both of a number of contrary properties.

Parmenides suggests that this conclusion is not problematic-he asks Aristoteles to 'concede these results as evident' (ibid) —before examining a similar hypothesis in the fourth deduction, this time for the others in relation to themselves. If the one is, the others are neither one nor many (159e); they cannot partake in the one because what is really one does not have parts, so the one cannot be in the others, and they cannot be many because to be many is to be one part of a whole, and we have concluded they in no way partake in the one. It is more difficult to prove the next claim: that the others are neither like nor unlike. Recall that we have demonstrated that if the one is, then the others are not many. A consequence of them not being many is that they are not two, as two is greater than one and is thus many. The property of being like is one property, and the property of being unlike is one property as well; combined, they are two. Thus, if the one is, then the others do not partake in both likeness and unlikeness. However, we have also concluded in this series that the others are not one. If likeness is one property, and unlikness is one property, then the others cannot partake in either of them, because if they did they would in some way be one (160a). From this, Parmenides promptly derives the familiar list of contraries, that the others 'are neither the same nor different, neither in motion nor at rest, neither coming to be nor ceasing to be, neither greater nor less nor equal' (ibid), because partaking in any of these properties would have the others partaking in either one or 
many, which they cannot do. Taken together, then, it seems as if this pair is in direct logical opposition; the same subject, the others, not only embodies contrary properties at the same time, but also does not embody either of them. That is to say, for property $F$, the others are both $F$ and $F$ 's contrary, while at the same time being neither $F$ nor con- $F$. Even if we take it to be possible for the others to be, for example, both limited and unlimited, we have to reconcile that with the claim that they are in addition neither limited nor unlimited. This seems like a potential problem for interpreters of Parmenides.

It makes sense to pause here to tie together the first four sets of deduction and the appendix to the first and second. Parmenides started by showing that the one, in the first deduction, is neither in motion nor at rest, nor like nor unlike itself, and so on and so forth. This ends with the claim, after discovering that it cannot partake in any number of contraries, that it does not exist and no account can be given of it. Re-examining the claim in the second hypothesis, he finds the opposite: that the one is both any number of contraries, and as a result embodies properties that it cannot seem to hold at the same time. To try to resolve this tension, he introduces time, showing that the one can be contradictory things as long as it does so at different times, and be nothing at all as long as it is outside time, in the instant. Whether or not this is successful is a matter of our interpretation. He then moves on to a discussion of the others that seems to follow the same pattern. First, Parmenides finds that the others embody contrary properties, before moving on to decide that they embody none of these properties at all. It seems, then, that his summary is entirely appropriate: Parmenides seems to have proven that both the one and the others are everything and nothing. It is remarkable, then, that he is willing to start the fifth hypothesis by saying: 'so far so good' (160b). 
The second set of four deductions are concerned with the consequences of the one not existing. The fifth hypothesis tries to deduce the consequences if the one is not for the one in relation to the others. As we should expect at this point, what he derives seems troublingly like a nest of contradictions. Parmenides finds that if the one is not, it must still partake in a number of forms. This is because when the proposition 'the one is not' is articulated, the speaker 'speaks of something...knowable...[and] different from the others' (ibid). In order for something to be knowable and have a difference in kind, it must partake in unlikeness, for example (161b). To speak truly, he claims, we must talk about the way things are, and to speak of things that are (162a). As a result, the one must be a not-being, if Parmenides is speaking about it truly; Parmenides finds that if the one is not, it must have a share in being (162b), and thus in some sense be, at the same time as not being. It must also be both in motion and at rest (162e), because to change from being to not-being implies a kind of motion, while being 'nowhere among the things that are' (162d) implies that it must be at rest, because to move requires somewhere to go. From this, it follows that the one is altered and not altered; altered when it is changing, and not altered when it is at rest (163a), and as a result both come to be and cease to bebecause what it is to change is to come to be $x$ and cease to be $y$-as well as not come to be and cease to be (163b) if it is not altered. The one that is not, then, seems as if it has the same problems as the one that is; it embodies a number of properties that are contrary, though Parmenides here makes it clear as part of reasoning that it does so at different times.

The sixth hypothesis considers the consequences for the one in relation to itself if the one is not. Whereas the fifth hypothesis insists on the being, in some sense, of not 
being, the sixth opens with the claim that 'what is not could neither be nor partake of being in any...way at all' (163c-d). Since it cannot ever partake in being, it cannot participate in any of the temporal qualifications of being: it cannot come to be or cease to be, either. If it cannot come to be or cease to be anything, then it cannot change, nor can it be at rest nor in motion, as these would be coming to be or ceasing to be a particular way (163e). Further, since it is not and as a result has no properties, the others can in no way be related to it; the others cannot be like or unlike nothing, as there is no basis on which to compare them to the one. Thus, the one of the sixth hypothesis seems to have (a) no properties of its own and (b) no properties in relation to other things; it 'is not in any state at all' $(164 \mathrm{~b}) .^{15}$

The last two hypotheses are concerned with the consequences for the others if the one is not. The seventh concerns the properties of the others in relation to the one. It finds that the others are both limited and unlimited, like and unlike, moving and at rest, and so on and so forth (165d). This results from the inference that if the one is not, the others must be other to each other, because otherwise they would be other to nothing at all and would not properly be 'other' (164c). These must be sets of unlimited multitudes, because if there is no one, then the others cannot partake in the one and thus must be infinitely many; that said, they must necessarily appear to partake in the one, because each unlimited mass of others is referred to as a single unlimited mass. Given that these unlimited masses are other from each other, and thus are not identical to each other, they must have limits relative to each other, but no limits internally, due to the absence of the one. Parmenides himself notes the pattern of the deductions here, mentioning that 'it

\footnotetext{
${ }^{15}$ It is worth noting that the sixth hypothesis seems explicitly to concern both the one in relation to itself and the one in relation to the others. This will be a major point of contention in the second chapter.
} 
would now be easy enough for us to go through' the familiar list of properties that the others both have and do not have at the same time (165e).

The final deduction is concerned with the properties of the others in relation to themselves. It finds more or less what we would predict at this point. If the one is not, then the others are neither many nor one (ibid), because manyness is a collection of ones, and there is no one in which to partake. Further, they cannot appear to be many or one, because it is impossible to conceive of many-greater than one-ness-without one-ness itself. As a result, and for familiar reasons, they are neither like nor unlike, neither the same nor different, neither in contact nor separate, and so on for the familiar list of properties (166b). The unusual aspect of the seventh and eighth deductions, though, is that here Parmenides explicitly makes a distinction between the appearance of a property and the property itself. He makes clear not only that the others are neither one nor many, but also further that they do not appear to be one or many, and nor can we conceive of them that way (166a). In summary, 'if one is not, nothing is' (166c).

Parmenides in the final lines of the dialogue ties together the strands of the eight arguments in an apt characterization of the previous hypotheses. He claims that 'whether one is or is not, it and the others both are and are not, and both appear and do not appear all things in all ways, both in relation to themselves and in relation to each other' (ibid). Unpacked, this seems to mean that if the one is, it embodies both a host of contradictory properties and no properties at all, as do the others; if the one is not, the same thing follows. It is hard to see how Aristoteles can respond to this by saying: '[v]ery true' (ibid). However, Aristoteles' response is the final line of the dialogue, and we get nothing further. Though brief, this should give us a general overview of what occurs in 
Parmenides, with special emphasis on those elements that will turn out to be of great significance both in our heuristic and in the next chapters.

\section{5: Parmenides' Features of Interpretive Significance}

As I noted at the start of this chapter, in order better to engage with Parmenides, it is necessary to identify the interpretively salient features of the text. These are the elements of the dialogue for which an interpreter must be able to account in their reading of Parmenides. For example, consider one of the central problems of Parmenides scholarship: what the connection is between the two major parts of the text. In the first part, Socrates articulates a rudimentary notion of the forms in response to Zeno and is brought to aporia by Parmenides; in the second, the style and topic of argumentation changes completely, and Socrates drops out of the conversation. Any reading of Parmenides has to be able to account for this radical difference between the two parts of the text. That is to say, they must be able to articulate a principled reason that Plato composes Parmenides as a single dialogue rather than two.

As Meinwald (2005) points out, though, we should not seek to explain only those elements that are unique to our text. As tempting as it may be to focus our reading entirely on those features that make Parmenides special, like Socrates' age or the strange quality of the arguments of the second part, the role of the interpreter is not restricted solely to explaining the distinctive elements of the dialogue. They must also account for the elements of the text that are apparently mundane, like the use of the standard dialogue form in the first part of Parmenides.

Identifying these interpretively salient features should help to parse proposed readings more thoroughly. First, I will identify the structural or literary elements of 
Parmenides. This includes but is not limited to character choice, genre of the dialogue, and temporal framing. Next, I will discuss the argumentative portions of the dialogue: the topics of the arguments, their form, their coherence, and so on. Finally, I will identify the salient extra-Parmenides features, such as the dialogue's relationship to the historical Parmenides and with other Platonic texts. I will identify the unique features of each category in sections of their own, and go through the common ones all together.

\section{6: Structural Features of Parmenides}

The first striking structural feature of Parmenides is its narrative framing. The events of the dialogue are communicated at a number of degrees of removal. Cephalus from Clazomenae comes to Athens fifty years after the conversation is meant to have taken place (Allen 1997: 70). He seeks out Glaucon and Adeimantus specifically in order to have Socrates' conversation with Parmenides and Zeno related to him (126b). Glaucon and Adeimantus do not know it by heart, so they take Cephalus to Antiphon-another relative of Plato's - who has the events of the day memorized. Antiphon himself, though, was not at the exchange; he had it related to him by Pythodorus, at whose house Parmenides, Zeno, and Socrates met, enough times to have committed it to memory (127a). Thus, the substance of Parmenides is removed from the reader on three axes. The dialogue is at least half a century distant from its report, and it is told at three degrees of removal; but further Cephalus is geographically distant from the events (126a). He emphasizes the difficulty and length of his journey to Athens explicitly to have the conversation between Parmenides and Socrates recounted to him. Meinwald (2005) asks what it is about this conversation that is important enough to have Cephalus cross the ocean; we can add the question: what it is about these events that is important enough that 
Pythodorus and Antiphon both perform the feat of memorizing the events of the day, and why do they interest Cephalus so many years later? Our reading of Parmenides then must have an account of the unparalleled significance of the discussion that takes place in Parmenides, as implied by its framing. In the same vein, we are not reminded of the narrative and temporal frame in the second part of the dialogue; there is no indirect discourse in Parmenides' engagement with Aristoteles, and the frame is never closed. That is to say, we do not ever return to Cephalus' story after we move in to Antiphon's; Cephalus, then, does not act in the same way that Phaedo does in Phaedo.

Second, Parmenides has three distinct parts to it: the preface, the elenchus that ends in aporia, and Parmenides' deductions. As I suggested at the start of this section, it is odd that there are such significant gaps between each section, stylistic and philosophical. Socrates drops out of the conversation at the end of the first part and is replaced by Aristoteles, and the topic of the discussion apparently changes completely; not only that, but the method employed in the second section bears little resemblance to that of the first, or any other style of argumentation in any other dialogue. Our reading must also then provide an account of why it is that Parmenides is one dialogue, as opposed to two; there must be a unifying element to the text that links Parmenides' engagement with Socrates over the forms and his hypothesizing about the one. Not only this, but we must have an account of the style of each section; we must be able to say why the standard dialogue form is used in the first, in addition to the different mode of argument in the second.

Third, the figures that are major characters in Parmenides are unusual. Not only is the title character a philosopher Plato takes quite seriously, ${ }^{16}$ he also chooses to have

\footnotetext{
${ }^{16}$ Cf. Sophist, Theaetetus.
} 
Socrates' typical position in the dialogue reversed, as well as putting emphasis on his relative youth. Socrates makes bold claims about the forms and then falls into aporia, instead of performing elenchus on the pronouncements of others. As Meinwald puts it, Socrates 'makes controversial assertions about special theoretical entities (Meinwald 1991: 5), assertions that are rendered problematic by Parmenides' investigation. It seems, then, that Socrates' role as questioned as opposed to questioner requires some explanation. The reversal of roles, and the presence of Parmenides, along with Zeno's small part to play in the dialogue in rounding out the company of influential philosophers, also begs investigation. ${ }^{17}$ The last 'major' character of the dialogue is 'Aristotle' or 'Aristoteles', depending on the translator. Generally, those that translate the name as Aristoteles are trying to help the reader to avoid the temptation to identify this character with the major philosopher by the same name. ${ }^{18}$ This is clearly tempting to any historian of philosophy, but Plato makes explicit that this Aristotle is 'the man who [long after the events of Parmenides] became one of the Thirty' (127d). This Aristotle is among the most passive interlocutors in Plato's work, and he never presents a serious challenge to Parmenides. He only expresses skepticism in response to an apparently dubious conclusion once, at the end of the first set of deductions. Indeed, this is explicitly why Parmenides chooses him; when looking for someone to answer his questions,

\footnotetext{
${ }^{17}$ Here, I use as a rough standard being mentioned extensively in texts by Plato's contemporaries primarily, Aristotle - for being an influential philosopher. This is obviously an imperfect standard, but I think that it delineates adequately between highly influential thinkers, like Zeno or Parmenides, and less influential ones like Thrasymachus. The former get mentioned more often - and taken more seriously than the latter; $c f$. Physics I.

${ }^{18}$ If we grant a standard developmentalist reading of Plato (that Plato's positions change over time, and Parmenides is late-middle in compositional order), then Parmenides is composed late in his life. At this point in time Aristotle would be starting to reach some degree of philosophical maturity. As such, we can see how it would be tempting to speculate that there is a commentary on the younger philosopher's views in Parmenides; however, this would be engaging in speculation that as of yet has seemed untenable.
} 
Parmenides says that the youngest 'would give the least trouble and would be the most likely to say what he thinks' (137b). More interestingly, though, Aristoteles seems to change his mind about a particular claim over the course of Parmenides' deductions. Though he expresses major reservations at the end of the first deduction about the conclusion that the one does not exist and cannot have an account given of it, he endorses this very same proposition both at the summary of the argument thus far at the end of the fourth deduction and at the overall summary of the dialogue, where he affirms Parmenides' claim that the one both is and is not all things in all ways is 'very true'. No interpretation of which I am aware has given an explicit account of why it is that Aristoteles has a change of heart about the knowability of the one through the second part of Parmenides, nor has this detail been noted.

By way of summary, it seems that we must have an account of both the apparent philosophical significance of the major characters in Parmenides and their particular roles played in the dialogue, whether Socrates acting as Parmenides' student or Aristoteles as the passive interlocutor who changes his mind. The minor characters of the dialogue are generally recurring figures: Adeimantus and Glaucon appear in Republic, as does a different Cephalus. As such, their presence is generally taken to tie Parmenides to Republic. The only information we have about Antiphon is that he was at one point passionate about philosophy, but in his age dedicated his time to caring for horses, as did his grandfather of the same name; Pythodorus, aside from being the host of the dialogue and being mentioned in Alcibiades as someone who paid a drachma to Zeno for lessons, is a mystery (Nails 2002: 259). Though the first three major characters require explanation, and the best imaginable reading of Parmenides would assign some 
significance to Pythodorus and Antiphon, it is not clear that we have enough information about the latter two to be able to parse out their significance in its entirety. We must then relax our standards slightly for these two minor characters. ${ }^{19}$

Finally, after Parmenides seems to give good reasons to be skeptical of the existence of the forms, he does not suggest that Socrates ought to abandon them. He claims that if someone does not grant the existence of forms, he will not "have anywhere to turn his thought, since he doesn't allow that for each thing there is a character that is always the same' $(135 \mathrm{c})$. That is to say, instead of objecting to Socrates' claims about the forms on his way to rejecting their existence entirely, Parmenides objects to Socrates' account of the forms without denying that there exist entities, themselves by themselves, that give characters to sensible objects. Given that he dedicates considerable philosophical energy to showing that this is an unjustified belief, it is surprising that Parmenides proceeds to try to rescue the hypothesis in the second part of the dialogue.

Consider in parallel one of the argumentative turns of Theaetetus. Theaetetus posits, when pressed, that knowledge is perception (151e), and Socrates provides a number of reasons why this is an untenable position. He does not try to salvage the thesis afterwards, either; instead, he simply moves on to another account of knowledge. This is the usual approach in Socratic elenchus: solicit a theory and then expose the theory's inconsistencies before discarding it. In doing this, though, it is important to point out that Socrates does not then reject the existence of the entity under investigation. It is clearly not the case that at the end of Euthyphro Socrates leaves thinking that there is no piety, or

\footnotetext{
${ }^{19}$ The reading I will propose over chapters two and three will be able to explain Antiphon's presence, but I have nothing to say about Pythodorus. I take this to be a flaw, but one that is neither fatal nor easy to remedy.
} 
that at the conclusion of Theaetetus he has successfully convinced all present that there is no knowledge. However, Socrates abandons these discussions after his elenchus; he does not invest any energy in improving Theaetetus' account of knowledge other than to show that it suffers from a number of flaws, and explicitly says that being left barren should improve Theaetetus' future philosophizing. However, Parmenides seems here to have a different project, in that he wants to salvage the forms but at the same time abandon Socrates' account. Thus, the distinction between the project of Parmenides and the standard Socratic method is not that Parmenides concedes the existence of the entities under investigation-Socrates does that all the time. Instead, it is that Parmenides seems to try in some way to buttress Socrates' thesis after refuting it.

We can summarize the structural and stylistic elements to be explained as a list of questions:

1) What is the significance of the conversation between Socrates, Zeno, Parmenides, and Aristoteles such that Antiphon and Pythodorus both went through the trouble of committing it to memory, and Cephalus made the difficult journey to Athens many years later to hear a third-hand account of it? Why do we never again mention any of the narrative frames after the preface? In most cases, when someone is relating a story from the past in Plato's dialogues, they occasionally interject with commentary or at least for the occasional '...he said'. In the second part of Parmenides, though, we are not even reminded that this is a recited account, and the narrative frame never 'closes' again; Cephalus, our narrator, never again appears. 
2) What is the connection between the two major parts of the dialogue? Why is it that they employ different modes of argument, and why is it that Socrates drops out of the conversation?

3) What is the significance of the characters present? Why choose Parmenides and Zeno to make whatever philosophical point is being made, and why is the Socrates of Parmenides the youngest Socrates Plato ever writes about? Why is Aristoteles the interlocutor for Parmenides, as opposed to Socrates, given that it is the latter's theory that requires Parmenides' input? Why does Aristoteles express skepticism about the conclusion of Parmenides' first deduction only when he first hears it?

4) Why is Parmenides' response to aporia in Parmenides different from Socrates' in similar situations, like Euthyphro or Theaetetus?

\section{7: Logical and Argumentative Features of Parmenides}

Perhaps the central feature of Parmenides is the apparently contradictory nature of the arguments of its second major portion. Specifically, Parmenides deduces a number of contrary propositions, often in close proximity to each other. As I noted earlier, it seems as if from the same starting point, he derives both the claim that the one 'is not named or spoken of, nor is it the object of opinion or knowledge' (142a) and that 'a name and an account belong to [the one], and it is named and spoken of (155d-e). Any plausible interpretation of Parmenides must give a reason that Plato would choose to create at least the appearance of contradiction. Second, it seems that the details and purpose of Parmenides' method requires some explanation. Recall that Parmenides, after prescribing training to Socrates, gives an outline of the type of exercise he should carry out. First, he 
tells Socrates that he must 'hypothesize' not only that which he wishes to examine, but also its negation. A strong interpretation of Parmenides must here give two pieces of information: (a) what 'hypothesizing' consists in in form and purpose, distinct from other modes of reasoning; (b) how the examination of the negation of a hypothesis is theoretically productive. Further, Socrates is meant to reason about a systematically determined set of consequences. This conceptual scheme requires some grounding; how is it that by focusing on the consequences for the object of hypothesis in relation to itself and in relation to others is productive? In addition, Parmenides frames this method by suggesting that Socrates should reason in the manner of Zeno when undergoing his training. It is a point of contention whether this implies that the kind of reasoning Parmenides describes is meant to bear some relationship to the paradox that Socrates ascribes to Zeno at the beginning of the dialogue. Finally, it seems that any reading of the method Parmenides agrees to give an example of must match up with the example that he actually gives in the latter part of the dialogue. That is to say, if our exegesis of Parmenides' method is in some way dissimilar to what seems to be his understanding of it, this requires some strong explanation. ${ }^{20}$

Third, we must take into account the quality of the objections to the forms that Parmenides gives to Socrates. It is worth noting first that Parmenides seem to suggest that his objections are not fatal ones for Socrates' theory; he claims that though '[o]nly a prodigy' (135b) would be able to resolve the objections he gives, he does not take them to be without potential resolution. This, taken in combination with the commonly held

\footnotetext{
${ }^{20}$ Though this seems like a trivial point on which to insist, it is a common criticism in the literature to claim that a particular exegesis of the Parmenidean method does not in fact map on to his example. $C f$. Meinwald (forthcoming), Gill (forthcoming).
} 
position that many, but not all, of the arguments of the first part are not exceedingly dangerous objections in the first place, ${ }^{21}$ seems to suggest that the objections given, even if they are taken to be good ones, are not designed to be fatal to the account.

Finally, if we take all the arguments of the second part to be valid, we must have an account of what precisely the argument is meant to establish. Parmenides concludes his argument by way of summary, saying that 'whether the one is or is not, it and the others both are and are not, and both appear and do not appear all things in all ways, both in relation to themselves and in relation to each other' $(166 \mathrm{c})$. We can either accept this as an actual statement of his conclusion as Meinwald does, or suggest that it is meant to spur us to find some other conclusion along with Gill, but either way we need an account of what precisely this perplexing line means, and how it is demonstrated by the preceding argument.

Our list of argumentative features, then, looks like this:

(1) What is the significance of the apparent contradictions in Parmenides' deductions? Are they actual contradictions or do they only appear to be that way? Specifically, it seems that the first two hypotheses have contrary conclusions that are derived from the same initial premise.

(2) How are we to understand Parmenides' methodological remarks? Can we both explain the goal of each step of the instructions, and parse out precisely what they mean? Further, how does the example of the second part work as an 'exercise'?

(3) Why does Parmenides articulate objections to Socrates' theory that he thinks are defeasible? Why does he not give the defeating argument?

\footnotetext{
${ }^{21} C f$. Forrester (1974) for an example.
} 
(4) What does Parmenides actually conclude at the end of his discourse, and how does he prove it?

There is a reasonable objection to my assertion that we can exclude the existence of bad argument in Parmenides as part of our heuristic framework. That is to say, it seems as if it overdetermines our reading from the start if we exclude what is commonly taken to be a major part of the interpretation of Parmenides; I have accepted the relatively controversial claim that all of the argumentation in Parmenides' deductions are good ones, or at least intended to be so, without a great deal of argument. Take as a sample of bad argumentation one of Patterson's (1999) examples: the argument that the one is in itself, and as a result always at rest, and that the one is in another and thus always in motion at 146a. He takes Parmenides' argument for the one always being in itself to be that '[ $t]$ he one, qua parts, is encompassed by itself qua whole; therefore, the one is in itself' (Patterson 1999: 99). From this, Parmenides deduces that if the one is always in itself, the one is always in the same place and condition. If this is the case, the one is always at rest. Patterson reconstructs Parmenides' argument for the one always being in another along the following lines: ' $[t]$ he one is not nothing; therefore it is somewhere. If the one is somewhere, it is either in itself or another. But the one is not in itself, [because] if the one qua whole, is in itself, then the whole is either in some of the parts or it is all of the parts. It is not in all the parts, because then the whole would be in one of the parts, which is impossible. And it is not in some, because then the greater would be the smaller, which is impossible. Therefore the one is not in itself; [t]herefore, the one is in another' 
(Patterson 1999: 99-100). If the one is always in another, the one is never in the same place or condition; thus, the one is always changing.

Patterson's objection to the first conclusion is that it does not follow from the fact that the one is in itself as a part of a whole that it is always in the same place or the same condition; it could, he argues, be spinning while remaining 'in itself' (ibid). A similar objection applies to the second conclusion: the fact that the one is in another does not mean that it changes between others, as it could consistently be in the same other and thus not be changing. This, then, seems like a transparently bad argument. ${ }^{22}$

In contrast, consider Rickless' reconstruction. If the one is always in itself, then the one is always in the same thing; if the one is always in the same thing, then the one is at rest. Similarly, if the one is always in another, then the one is not ever in the same thing and hence never at rest. If the one is not ever at rest, then the one is always in motion (Rickless 2007: 152). Rickless directly responds to Patterson's criticism, arguing that if we understand the implicit definition of 'to be at rest' that Plato is using, this is not a problematic argument and it does not equivocate. Rickless argues that if we are to charitably reconstruct the argument, we must understand what he calls 'PE1', or the first principle of elision: that to say that $x$ is $F$ in some way is to say that $x$ is $F$. To say that the one is at rest, then, is only to say that 'in some respect or other', the one is at rest (ibid). Rickless gives the example of a ball; if someone is holding a ball in their hand, and their hand is moving, then the ball is moving relative to some stationary point, but is at rest relative to the hand. If this is the case, Parmenides does not have to show that the one being at rest entails that the one is in all ways and cases in the same condition: he is

\footnotetext{
${ }^{22}$ M. L. Gill (1996), too, chooses this as an example of an invalid argument in Parmenides.
} 
The Problem of Parmenides

simply obligated to show that relative to some sphere of discourse, the one is in the same condition. Though the one could be spinning like a ball on a person's hand, the one is at rest relative to that hand, and that is all Parmenides is claiming to demonstrate. As such, though the argument seems like a bad one, it is only problematic if we do not bring out the assumptions Rickless takes to be implicit. As such, I am inclined to take Rickless' analysis to be the best available for the validity of the arguments of the second part of Parmenides; as a consequence of this, it is best for now to take all of the arguments to be intended to be valid.

\section{8: Features External to Parmenides}

Finally, we have to account for how well our reading of Parmenides matches up with both other Platonic dialogues and comments by Plato's contemporaries. First, regardless of whether we grant a developmentalist framework or not, Parmenides can safely be assumed to bear some relationship to other dialogues. Arguments have been made primarily for Parmenides being linked to other dialogues that are generally understood to be metaphysical, including Sophist and Statesman, as well as Theaetetus, Timaeus, and Philebus. ${ }^{23}$ However, these need not be the only connections between Parmenides and other dialogues. For example, I will argue in chapter three that it is profitable to compare Parmenides to Meno, Phaedo, and Republic, and that indeed the latter comparison is explicitly justified by the framing of the dialogue..$^{24}$ In our reading of Parmenides, though we need not make any of these specific links if we have compelling reasons not to, we should expect that some account can be given that connects the dialogue with some of the

\footnotetext{
${ }^{23} C f$. Tumbull (1998), Gill (forthcoming), and Rickless (2007) for examples of arguments for links to these dialogues.

${ }^{24}$ Constance Meinwald (2005) has written an informative article on the potential links between Republic and Parmenides.
} 
others: it should not have a conclusion that is entirely out of step with everything else Plato composes. That is to say, even if it is entirely at odds with the 'standard' reading of another dialogue, we should be able to give a good reason for why that would be so. For example, many of those who take Parmenides to be a discussion entirely of the properties of the forms find that the arguments Parmenides makes in both the first and the second part are a criticism of what they take to be the standard theory of forms. ${ }^{25}$ If Parmenides is composed of criticisms, then it makes sense that it is distinct from the rest of the corpus. Similarly, we should not limit our account of cohesion between the dialogues to philosophical cohesion. It is worth noting that Plato makes it explicit that Socrates is at his youngest in Parmenides, which makes this dialogue the earliest point in our account of his beliefs. If our interpretation suggests that Socrates must hold a belief that the later Socrates-for example, the Socrates of Phaedo-does not hold, then it seems that while we may not be philosophically inconsistent, we are being temporally inconsistent. ${ }^{26}$ The old Socrates should hold the same beliefs as the young Socrates if the beliefs of the young Socrates are correct. If this is not the case, this is clearly a drawback for our reading, though not a fatal one.

Second, it would be a benefit if our reading of Parmenides could reasonably explain some otherwise opaque lines that Aristotle writes on Plato, or perhaps show some influence from Plato to his students. For example, Mitchell Miller (1995) has written a lengthy essay to suggest that much of what Aristotle attributes to Plato's 'On the Good' can be sourced in Parmenides. Though this is highly speculative, and produces a reading

\footnotetext{
${ }^{25}$ Cf. Rickless (2007), Gill (1996; forthcoming).

${ }^{26}$ I will return to this in chapters two and three, but in brief, I am not sure that narrative inconsistency is a particularly large problem with any potential reading, and can easily be explained.
} 
that may not be viable, the spirit of the exercise is valuable, in that it helps to explain readings of Plato generated by his contemporaries. In a similar vein, Dillon (2005) suggests that a particular reading of Parmenides helps us to understand what little we know of Speusippus' metaphysics, which otherwise seems to bear little resemblance to his teacher's views; and, Cornford (1939) has suggested that his understanding of Parmenides helps to explain why Aristotle in Physics routinely notes that the word 'one' and the word 'is' are both highly ambiguous, and suggests Plato has a similar notion. Similarly, Palmer (1999) has argued that Parmenides borrows arguments from his predecessors, including specific passages from Gorgias (Peterson 2003: 253). Though we should be cautious in asking of our reading that it explain this sort of data, it seems to be a benefit if an otherwise-plausible reading additionally helps to explain connections with Plato's contemporaries. That said, it should not be necessary; the first direct commentary we have on Parmenides in Proclus is long after Plato. Finally, we should keep in mind how well Plato's character agrees with what the actual Parmenides' writing.

It seems, then, that we can summarize the questions to be answered based in external sources as follows:

(1) What are the connections between Parmenides and other dialogues? If our reading is not consistent philosophically or temporally with other dialogues, can we give an account as to why that is the case?

(2) Does our reading of Parmenides help us to explain connections with other thinkers, or remarks they make about Plato that otherwise seem to be puzzling?

(3) Does the Parmenides of our reading of the dialogue line up with Parmenides' proem? 
Again, it must be emphasized that these are not necessary conditions for an acceptable reading of Parmenides. The latter two questions of this set are substantially more speculative than the rest; the first, I think, should be answered by any good reading of Parmenides, and can be without unduly speculating. A strong reading of Parmenides seems as if it would answer all of these questions, and this heuristic framework should make it easier to see what each of the interpreters in the next chapter is arguing and what they are using to support their claims, as well as highlight the precise shortcomings of each proposed interpretation. 


\section{1: Methodological Remarks}

Now that we have established a heuristic to aid us in comparing readings of Parmenides, it is worth outlining how I plan to assemble these readings for evaluation. It is clearly not possible to put forward a charitable characterization of every reading of Parmenides, or even a particularly significant number, in the amount of space I have available. As a result, I will examine the interpretations of Constance Meinwald and M. L. Gill primarily, as exemplars of their respective interpretive camps. They are typically divided, roughly, down the line that Proclus traces in his Commentary on Parmenides: a metaphysical interpretation and a logical (or gymnastic) interpretation. ${ }^{27}$ Meinwald's and Gill's readings will operate as the 'cores' of the interpretations that I will present, though I will occasionally draw on other thinkers that write in support of one of them. For example, Sandra Peterson has responded to a number of objections aimed at Meinwald's position from Gill, and in cases where Meinwald herself provides no compelling answer, I will draw on Peterson in an attempt to defend her position. Further, when no author in a particular camp seems to address an element of Parmenides that requires explanation, I will try to make a modest extension of the view under discussion and explain that part of the text in a way that seems consistent and organic with the rest of the reading. The first section of this chapter will be devoted to developing what I take to be the strongest version of the gymnastic thesis. In it, I will draw on Constance Meinwald's influential

\footnotetext{
${ }^{27}$ It is worth noting, as Constance Meinwald has pointed out, that there is not a clear distinction between these two types of enterprises in Plato and Aristotle. As she puts it, predication and metaphysical difference are not disjoint in their views; indeed, they are closely tied. As a result, these categories are somewhat suspicious, and almost certainly anachronistic. To this I say that these terms are used here not to denote anything substantive about the content of the positions aside from the fact that they belong to certain interpretative histories that are distinct. Thus, these are simply used to refer to these readings for tradition and clarity's sakes, not for a more philosophically profound reason. As a side effect of the way I use these terms, I will not say a great deal about the history of the distinction; though it is intrinsically interesting, it is not relevant to the interpretation of the Parmenides.
} 
Plato's Parmenides (1991), as well as her more recent published and forthcoming work. The next section will develop what I take to be the strongest possible metaphysicalist account. In doing so, I will draw on a number of authors, but my primary source will be M. L. Gill's forthcoming work, as it will be used as the scaffolding for the central thesis. Other major authors that will be central in making this thesis plausible will be Samuel Rickless, Mitchell Miller, Kenneth Sayre, and Samuel Scolnicov. The goal of this chapter, then, is first to establish two strong possible interpretations of Parmenides, as measured by the framework that I have outlined, and second to show that on examination, these two interpretations collapse into one, stronger reading.

\section{2: The Gymnastic Approach to Parmenides}

The gymnastic approach has traditionally held two claims about Parmenides to be central to coming to an understanding of the dialogue. First, the gymnastic interpreter thinks that the central positive philosophical innovation of the dialogue is a linguistic or a logical one; second, the gymnastic thesis holds that we can understand Parmenides best as a logical exercise that, when repeated, improves our philosophical capability. Meinwald articulates a variant of this position in 'How Does Plato's Exercise Work?'. The Parmenides 'is designed to spur us to develop an understanding of a distinction between two kinds of predication and indeed two metaphysically different kinds of facts about forms' (Meinwald forthcoming: 1). That is to say, by making clear the distinction between two different types of predication, Parmenides is meant to give the reader the tools necessary in order to engage with critics of the forms. It is worth noting that this distinction, though explicitly a linguistic-logical one, has major metaphysical implications; a study of the linguistic act of predication is also for Parmenides a study in 
how it is that sensible objects and forms possess properties. ${ }^{28}$ Essentially, she understands Parmenides to be 'homework'; it requires the reader 'to do something, to engage in philosophical activity', as opposed to absorb doctrine (Meinwald forthcoming: 8). Meinwald's variation of the gymnastic thesis seeks to demonstrate three points:

(1) Parmenides is meant to help the reader develop her own solutions to the problems of the first section, not to give those answers directly. ${ }^{29}$

(2) These solutions are rooted in coming to an understanding of two particular kinds of predication, made explicit in the methodological remarks at the transitional passage of the dialogue.

(3) Parmenides is demonstrating that the form of the One is a plausible candidate for an arche [first principle]. ${ }^{30}$

In order to demonstrate (2), Meinwald argues that Parmenides articulates a distinction between predication pros heauto and predication pros ta alla. What precisely this distinction is is a matter of some controversy in the literature. Translated, the two phrases roughly mean 'in relation to itself' and 'in relation to the others' respectively; that is to say, $x$ is $y$ in relation to itself, and $x$ is $y$ in relation to the others. In order to understand the two types of predication, I am going to develop a contrast between Gill's characterization of Meinwald and what Meinwald actually thinks is present in Parmenides. Gill claims that in Meinwald's view a pros heauto feature is a definitional feature, and a pros ta alla feature is a non-definitional feature (Gill forthcoming: 7). This

\footnotetext{
${ }^{28}$ Note here, then, why she is so deeply suspicious of the logical-metaphysical distinction.

${ }^{29}$ Cf. Meinwald 1991, pp. 153-163.

${ }^{30} \mathrm{Cf}$. Meinwald forthcoming, p. 2, fn. 4 . I am going to be setting any discussion of this aspect of Meinwald's thesis aside until the next chapter for two reasons. First, this is not a position that Meinwald argues for thoroughly; second, it is not a claim on which the rest of her thesis rests.
} 
is very nearly correct, and is a good starting point for our investigation; however, Meinwald has a minor quibble with the possible implications of this reading. She argues that a property that an entity has pros heauto is not, strictly speaking, a feature at all. Thus, it clearly cannot be a definitional feature. However, on another gloss of 'definitional' Gill's reading of Meinwald is correct. If we understand 'definitional' to mean simply that ' $A$ holds of $B$ as a matter of definition' (Meinwald forthcoming: 15), or that 'the nature of $A$ is a proper part [or whole] of the nature of $B^{\prime}$ ' (ibid), then we are much closer to what Meinwald is means. That is to say, $x$ is $y$ pros heauto if $y$ is part of the account or definition of $x$, but $x$ need not display $y$ in order for it to be part of the account. This distinction is illustrated best by an example. Consider the proposition 'the book is rectangular'. We understand this to mean that the referent of the book has the property of being rectangular, which can be broken down to mean that the book has four sides, and those sides are of equal length to their opposites, but not to the sides adjacent to them. ${ }^{31}$ If we were to say 'the book is rectangular pros ta alla', we would be claiming, in Meinwald's view, that 'the book' bears a relationship to Rectangularity, which gives it the property of being rectangular. That is to say, the book (the subject) comes to possess the property of being rectangular (the predicate) by virtue of a relationship with the form of Rectangularity (a third entity, 'the others'), which is an ousia [substance, form] ${ }^{32} \mathrm{We}$

\footnotetext{
${ }^{31}$ When I use 'Rectangularity', or 'the property of being rectangular', in the proceeding passages, I mean for it to refer to this bundle of properties; I take it to be shorthand for 'having four sides that are equal to their opposites but not to the sides adjacent them'.

${ }^{32}$ Let us here address a preliminary question. It seems odd to make the claim that 'the book is rectangular in relation to the others' means that the book is rectangular in relation to the form of rectangularity, which is clearly a singular entity. 'Pros ta alla', though, picks out a general category of predication, not just an individual instance of that category. That is to say, pros ta alla is a type of predication, in which subjects bear a relation to predicates, not a token of that type, in which a subject refers to a predicate. This phrase occurs in the methodological remarks that are to communicate the general plan of the deductions, not in a particular instance of those deductions. Further, we could make the claim that most entities have more than
} 
can call this a relation to the 'others' because an ousia 'will typically be distinct from individuals whose display of features it explains' (Meinwald forthcoming: 12). Using the example of being unlike, Meinwald claims that 'anything's being unlike must be due to its standing in a relation to the relevant ousia' (ibid.). Green is then unlike red in relation to the ousia of Unlikeness. Thus, we can see how it makes sense to refer to this kind of simple predication as pros ta alla, as there is a second entity to which the act of predicating makes reference.

It is worth noting that forms can have pros ta alla relations to other forms, too. Take for example, the proposition that 'there is one form of the Good'. This means that there is a pros ta alla relationship between the One and the Good, and can be understood as the claim 'the Good is one pros ta alla'. Thus, pros ta alla picks out a particular category of predication in which two subjects—one that has a property, and one that provides the first with that property-interact. This, it seems, is our typical understanding of how predication works for Plato. A claim that $x$ is $y$ pros heauto, though, is of a different type of predication with a different meaning. Meinwald suggests that these claims are to be understood as 'articulations of natures' (Meinwald forthcoming: 13). She argues that pros heauto properties do not have to be displayed in any way. That is to say, something can have a property in a sense aside from instantiating that property. Instead, $y$ 'appears in the specification or account of what it is to be [x]' (Meinwald forthcoming: 13). Note specifically the use of the word 'account' here, to be understood as having the same force as the Greek logos. Consider the form of the Rectangle. The proposition 'The Rectangle 
is rectangular' need not mean that the rectangle actually displays four sides; this would require that the Rectangle were extended, which is clearly impossible. Instead, if we say 'The Rectangle is rectangular pros heauto', we are instead claiming that the Rectangle has as a part of its account that it is rectangular. That is to say, again, Rectangularity has as part of its account four sides that are equal to their opposite side and not to their adjacent side. This is trivially true, but illustrates an important point about a particular kind of predication: in abstract, $x$ can be predicated on $y$ not as a claim about the display of properties, but instead a claim about the definition of $y$. Pros ta alla predication, then, is the relation of a subject to an ousia, and pros heauto predication is the relation of a subject to its account. ${ }^{33} \mathrm{~A}$ full pros heauto account of a concept, then, would be a complete definitional analysis.

This interpretation of the pros heauto/pros ta alla distinction, combined with the gymnastic 'homework' account, solves a number of problems for the reader of the Parmenides. However, before moving on to the benefits of this reading, it is first worth addressing an intuitive objection. It seems implausible to import a complicated and nuanced account of different kinds of predication into the dialogue that is nowhere in Parmenides explained. If Plato's goal is to communicate this distinction, then it is clear that he could do a much better job by actually writing about it explicitly, or giving better hints.

\footnotetext{
${ }^{33}$ There may here be an objection to this account based on what the word pros means. It seems that the pros + accusative construction implies some sort of distance between the subject and the predicate of the phrase; pros often implies a spatial or a temporal relationship. This would be a problem for any claim being pros heauto, as this would necessitate a distance from the self. However, pros has a third sense in the accusative in which it can be causal or 'in respect of', which is the sense in which it is here being employed.
} 
To this, there are two rough answers. First, it must be noted that what makes Parmenides' methodological remarks so obscure at the transitional part of Parmenides is his inclusion of the relational qualifiers; if he were simply to say that Socrates must derive the consequences of his hypothesis and its negation, but not include that he must derive those consequences pros heauto or pros ta alla, there would be nothing especially challenging about his instructions, and there would be no good reason for Socrates to request the clarification that results in Parmenides' cryptic exercise. This seems to suggest, at the minimum, that the pros phrases are central to figuring out how the second part of the dialogue works, though it is insufficient to prove Meinwald's particular reading of them. However, it does mean that an examination of the way predication functions in Parmenides is required, and seems further to suggest that the solution to Socrates' problem in the first part of the dialogue is one that can be found in an examination of the relational qualifiers. It should then count in favour of Meinwald's theory that she makes use of these qualifiers in order to resolve Parmenides' objections to Socrates.

Second, it should not cause us too much pause that Plato does have Parmenides discuss his use of these distinctions for a few reasons. First, and perhaps most simply, good pedagogy is not restricted simply to communicating a particular piece of information to be committed to memory; it is better to have, for particularly difficult solutions, the student come to an understanding by reasoning through the problem on their own. This seems to be the strategy that Parmenides employs to teach Socrates how better to articulate the forms, and is the strategy Socrates employs in his role as a midwife; it is not implausible to think that Plato is employing the very same type of 
pedagogical method that Parmenides does here. Second, requiring of the reader difficult exercises is not without precedent for Plato scholarship. As Meinwald notes, Myles Burnyeat identifies 'a graded series of increasingly challenging tasks that Plato sets readers in connection with each of the proposals about knowledge' (Meinwald forthcoming: 8). That is to say, this is not an assertion unique to Meinwald's reading of the Parmenides. ${ }^{34}$ Finally, given Plato's apparent skepticism of the suitability of the written word for philosophy in Phaedrus and Seventh Letter, it is consistent for him to draw the reader into a dialectical problem that is not solved by committing the words on the page to memory, but must be reasoned through independently. Though none of these responses are on their own enough to render certain Meinwald's claims about the pros phrases, taken together, they seem to suggest that this solution is at least initially plausible. By examining the advantages of this example of the gymnastic approach with reference to the heuristic I established in the previous chapter, this construal of the pros phrases may be made more compelling.

The first part of the heuristic framework it meets is the presence of apparent contradictions between deductions. ${ }^{35}$ Consider a sample contradiction between the conclusions of the first and second deductions. Parmenides concludes at 142a that the One is 'not named or spoken of, nor is it the object of opinion or knowledge', and at $155 \mathrm{~d}$ claims that there is 'knowledge and opinion of perception of [the One]'. In Meinwald's

\footnotetext{
${ }^{34}$ Further, this same objection could be launched against any reading of Parmenides that holds that Parmenides is giving Socrates the solution to his objections in his exercise; no matter what, it is clear that he does not directly communicate this innovation.

${ }^{35}$ It is worth noting here that the pros phrases cannot solve the intradeduction contradictions, as has been pointed out by Gill (forthcoming), and Sayre (1996). To this, she has responded that the pros phrases simply are not designed to address this problem (Meinwald forthcoming: 19). She claims that these do not require the application of pros phrases because they are not contradictions at all. I address this issue below.
} 
framework, the first deduction is pros heauto predication, and the second is pros ta alla. Thus, the form of the One does not have as part of its account that it is the object of knowledge, that it exists, or that it can be named. ${ }^{36}$ However, this does not prevent the form of the One from actually being known; it simply means that it is only known contingently. We can see how this would be the case. If there were no entities in the universe that were capable of cognition, then the form of the One would still exist, but it would be unknown. Thus, it cannot have as part of its account that it is known, because this is not necessarily the case. However, the form of the One can be in a relation of knowability, as the universe in which we exist does contain entities capable of cognition; the One is known pros ta alla, in relation to us (or at least Parmenides). It is known pros ta alla, then, but unknown pros heauto. Thus it seems that if this maps on to the rest of the inter-deduction contradictions, the gymnastic approach is capable of finding some sort of explanation for apparently contradictory conclusions in the latter part of

\footnotetext{
${ }^{36}$ There is an ambiguity here that could cause a great deal of difficulty. We can understand the negation in this line to mean one of two things: (1) that it is not part of the account that the One can be spoken of, or (2) that it is part of the account that the One cannot be spoken of. These mean importantly different things; if (2) is the case, then it is not possible to assert that the One can be spoken of pros ta alla, because that is definitionally impossible, as opposed to just definitionally not the case. To see this ambiguity, consider the proposition 'The Dog does not have three legs pros heauto'. We can take this to mean one of two things with vastly different consequences. Either the Dog (1) as a matter of definition does not have three legs or (2) does not, as a matter of definition, have three legs. If we take (1) to be the correct reading, then no dogs pros ta alla can have four legs, because they would also have three; if we take (2) to be true, then we have our standard notion of a four-legged dog preserved, as it is simply asserting that the account of Dog does not include that they have three legs. This ambiguity is present in the Greek as well. There is some reason to think, though, that the gloss that reads the phrase as asserting that it is not part of the account of the One that is spoken of is the better one. If it is true of the One that it cannot be spoken of, then we have an instance where the context of an argument clearly falsifies it; it certainly seems as if Parmenides has been speaking of the One at great length, and will continue to do so for thirty more Stephanus pages. For this reason, Aristoteles expresses skepticism. However, as I noted in the previous chapter, Aristoteles changes his mind about this assertion through the course of Parmenides' exercise, as he affirms the summaries at the fourth and the eighth deduction. As a result, it does not seem felicitous to the text to accept a gloss of the first deduction that is clearly false. If instead we understand the passage to mean that the one does not have as part of its account that it is known - that is, that the One can exist without beings capable of knowing we do not make Aristoteles a poor interlocutor.
} 
Parmenides; Plato is spurring us to develop the distinctions necessary to see how these sets of deductions are not necessarily in conflict.

Second, this distinction clarifies the connection between the engagement that Parmenides has with Socrates in the first part of the dialogue and Parmenides' deductions in the second part. If the homework Plato assigns to the reader is to develop these distinctions in predication, and she can resolve Parmenides' objections to Socrates in using the pros phrases, then the gymnastic approach can claim that the connection between the two major parts of the dialogue is that the lesson of the second is applied to solve the problems of the first.

Meinwald's solution must be understood in contrast to what she calls 'scarequotes "Platonism"" (Meinwald 1991: 153). This is the view that Plato holds that forms are 'superexemplifications' of the properties to which they correspond; Beauty is maximally beautiful, Justice is maximally just, and so on and so forth. Understood this way, all predication is pros ta alla predication: 'The Just is just' describes the very same relationship as 'Aristedes is just' (Meinwald 1991: 154). Meinwald argues that this is absurd; on a pros ta alla-exclusive account of predication, 'The Rectangle is rectangular' is obviously untrue. If part of being rectangular is displaying the property of having four sides, then unless the Rectangle is extended, it cannot display its own property. Pros heauto, however, 'The Rectangle is rectangular' can be true. Part of the account of the Rectangular is rectangularity; by definition, the property of Rectangular includes that there are four sides, each of which is equal to their opposite, and so on and so forth.

This distinction, then, can save Socrates from objections that involve selfpredication like the Third Man. Recall that a simplified version of the Third Man 
objection goes something like the following. In order for a sensible and a form to have a certain property in common, there needs to be a third entity that explains the resemblance that the first two have. Parmenides argues that if the Large is large, and forms are explanatorily useful partially because they provide an answer to the question 'What do all $x$ things have in common?', then the Large and all other large entities must have a further entity in common to account for their similarity. Now, this objection only has teeth if we understand proposition (1), 'The Large is large', as a case of pros ta alla predication. If we articulate (1) as if it is pros ta alla, we find that this means that the Large is large in the same way as a football player is large and the Empire State Building is large; it bears a relationship to the form of Large. However, if we understand (1) pros heauto, the paradox dissolves. We can assent that (1) is true, but only trivially; large is part of the account of Large, insofar as part of Large is largeness but that does not mean that it displays the property. Instead, largeness is part of what it is to be large (Meinwald 1991: 156). As a result, the Empire State Building and Large are not in the same way large. The first displays the property pros Large; the second does not display the property, but is large pros heauto. Thus, we do not have to posit a third entity that Large and the Empire State Building have in common.

A similar answer can be brought to bear against Parmenides' dilemma about participation of sensibles in the whole of forms or in parts of forms. Socrates, recall, tries to claim both options to no avail. If an object participates in the whole of a form, then it seems that two large objects both have the whole of Large. If two large objects have all of Large, then Large is different from itself, because it is wholly present in two different sensibles, which is not possible. On the other hand, if large objects participate only in a 
part of Large, then it is strange to claim that that object is large by virtue of having a part of Large that is smaller than Large, assuming that we understand predication strictly pros ta alla still (Meinwald 1991: 158-159). It seems, then, that neither option is a desirable account of participation. If we understand (1) pros heauto, though, this problem dissolves. If Large is definitionally large, but does not display the property itself, then the part/whole distinction becomes largely incoherent, because if Large does not have to display its own property, then it does not give 'smaller' pieces of itself to large entities, nor does it 'inhabit' large entities in any way that would make it different from itself. As long as Large acts as an account as opposed to a superexemplification, Parmenides' participation problem is a non-issue. Recall that the difficulty for Socrates here was that it was unclear how the forms and the world of sensibles could interact. Consider as an example chemistry. Chemistry has as the object of its knowledge chemicals, like hydrogen. Parmenides argues that though Chemistry itself has knowledge of Hydrogen itself, and chemists have knowledge of hydrogen, it is not obvious how Chemistry itself can have knowledge of hydrogen, and how chemists can know Hydrogen itself. Meinwald's solution is to have us straightforwardly apply the pros heauto/pros ta alla distinction. Chemistry knows Hydrogen pros heauto; that is to say, the correct account of Chemistry includes that it is the knowledge of Chemicals, including Hydrogen. ${ }^{37}$ However, it is not, as a matter of account, the case that Chemistry knows hydrogen. Thus, we can say that Chemistry does not know hydrogen pros heauto. However, from this it

\footnotetext{
${ }^{37}$ The reason the initial proposition, that Chemistry knows Hydrogen, seems to get our backs up logically is that it seems to make no sense if it is pros ta alla predication; how could a form without a mind display the property of having knowledge? However, if we take Parmenides' objection that the Master is the master of the Slave, then it seems that forms in some sense have to stand in these sorts of relations, but it is unclear how this is possible. This illustrates why we require a separate account of predication.
} 
does not follow that Chemistry does not know hydrogen period-Parmenides' claim, understood pros heauto, does not actually disqualify Chemistry from knowledge of sensibles, and it further does not disqualify us from knowledge of Hydrogen. It simply notes that these relationships do not hold solely as a matter of definition; we are perfectly capable of knowing Hydrogen pros ta alla, but in a world without entities capable of knowing, Hydrogen would be unknown.

Thus, we can see how Meinwald's thesis holds that the relationship between the two major portions of the dialogue is that the pros distinction that Socrates should come to understand at the end of Parmenides' demonstration is capable of resolving Parmenides' objections in their engagement on the forms. The pros heauto/pros ta alla distinction that is developed via the homework assigned by Parmenides, then, straightforwardly addresses three of the major textual elements: (1) the apparent contradictions between deductions, (2) the relationship between the two major parts of the dialogue, and (3) part of the content of Parmenides' methodological remarks. Further, it matches up with one of Aristotle's recurring remarks, that is 'is used in many ways, so we must consider in what way the word is used' (Physics 185b7); though this in itself does not prove that the way predication works is central to Parmenides, that it is a major concern of Aristotle's at least opens up the possibility that this could be a concern for Plato, too.

The presence of contradictions between lines internal to a single deductive set, though, seems to speak against the gymnastic hypothesis; as Sandra Peterson has noted, is not obvious what value there is in repeating fallacies and contradictions. However, as I 
noted above ${ }^{38}$ the gymnastic approach need not think that these contradictions are really contradictions at all. Take as the most blatant example the results of the second deductive set. Parmenides claims that 'the one itself both is and comes to be older and younger than itself and the others, and it neither is nor comes to be older or younger than itself or the others' (155c). This does not initially seem to be a useful result, and looks as if it is in obvious violation of the law of non-contradiction. However, it does not follow from the fact that we can arrange such statements as 'the one is $F$ and not- $F$ ' that they are actually logically problematic. ${ }^{39}$ Meinwald argues that such claims 'are no offense to logic as long as the most fully specified description of the state of affairs in question passes the test' (Meinwald forthcoming: 20). For example, George can be both equal and not equal to Thomas, by being equal in height but unequal in organizational rank, or equal in speed but unequal in skill at juggling. By giving the requisite details to fill out the proposition entirely, the law of non-contradiction does not cause Parmenides difficulty. This works in the case of the example at $155 \mathrm{c}$. Parmenides claims immediately prior to this line that the difference in ages will constantly be the same, but the ratio changes over time. As a result, the one neither is nor comes to be older or younger than itself or the others because the absolute ages of each entity are stable; however, their relationship changes if understood as a fraction. If I am six years old, and my friend is seven years old, I am currently six-sevenths her age. A year from now, though, I will be seven-eighths her age. This line of thinking - especially regarding the results of the second deduction - is

\footnotetext{
${ }^{38}$ Chapter 2, fn. 35.

${ }^{39}$ Here someone might object that this really is not the major problem in Parmenides' demonstration; it is not the statements themselves that are the problem, but Parmenides' reasoning. Here, I refer back to chapter one in my endorsement of Rickless' analysis of the second part of Parmenides. I claim with Rickless that the arguments are largely valid if we understand the assumptions Parmenides works with properly. There is no 'magic bullet' for reading these arguments, but simply working through them carefully and charitably.
} 
actually reinforced by the appendix to the second set. Here, Parmenides reasons through the implications of the one participating in time, and fills out the state of affairs sufficiently for the case of the one coming to be older and younger than itself and the others to be unproblematic. Thus, intradeduction contradictions are not a difficulty for Meinwald, as they simply do not exist. ${ }^{40}$

Granting these claims, it seems that the gymnastic approach has further interpretive power. Meinwald's account also lessens, if not wholly eliminates, the problem of the puzzling last two lines of the dialogue. After Parmenides claims that the one is and is not all things in all ways, Aristoteles, recall, replies that this is 'very true'. If we take Parmenides' statement to be contradictory, then Aristoteles' assent is troubling. To this, one might reply that Aristoteles is a weak interlocutor; he seems to give Parmenides a pass on some statements that clearly require clarification. However, though Aristoteles is unwilling to challenge Parmenides, he has demonstrated his willingness in the dialogue to express puzzlement, asking Parmenides what he means at a number of points. The strength with which he agrees to Parmenides' strange final statement seems to suggest that it is unproblematic and obviously true; if the final proposition is taken as Meinwald understands it, it is unsurprising.

This, however, raises a further problem. Aristoteles does, at one point in the deductions express some skepticism about Parmenides' conclusions beyond a simple call for clarification. In response to Parmenides' query at the end of the first deductive set as to whether his conclusion—that the one is not named or spoken of, nor does it exist- 'is

\footnotetext{
${ }^{40}$ This is in line with Rickless' (2007) reading, and dissolves the sample contradiction with the same strategy.
} 
possible...for the one' (142a), Aristoteles baldly asserts that this seems impossible. If Aristoteles denies the results of the first deduction but affirms the conclusion that confirms in, he looks to be in a contradiction; this suggests one of two things: either (a) Aristoteles is even worse an interlocutor than he seems or (b) his position on the first deduction changes during the course of Parmenides' demonstration. Both of these possibilities bear some textual support. When selecting Aristoteles for the job of interlocutor, Parmenides emphasizes that he wants the youngest because he will give the least trouble. This seems consistent with claim (a), and would suggest that Parmenides is looking to bully Aristoteles into submission with a torrent of dense and occasionally bad argumentation. However, I do not take this to be an especially philosophically fruitful line of reasoning; this would seem to reduce Parmenides to a reductio of Parmenides' philosophy and character as a philosopher, which given Plato's apparent respect for Parmenides in Sophist, Theaetetus, and Statesman, and the effort which must have gone into the composition of Parmenides, seems to be an unlikely project. Thus, we should only accept (a) if (b) proves to be unsupportable, and I do not think that that is the case.

If the gymnastic account is right, and one of the aims of Parmenides is to assign 'homework', and that that 'homework' is partially to develop the pros heautolpros ta alla distinction that makes the final summary unproblematic, then it does not seem much of a stretch to suggest that Aristoteles is working alongside the reader (though he certainly seems to be successful much more quickly than the rest of us are!); that is to say, in the first deduction, Aristoteles does not yet have a conception of pros heauto predication, and by the end of the eighth, he does. If he has developed this notion, then he can assent to the summary enthusiastically even though he had initially balked at the first conclusion. 
Thus, it seems as if Meinwald's view is capable of explaining Aristoteles' behaviour by suggesting that Parmenides is trying to have Aristoteles and Socrates develop the pros distinction.

Meinwald also has a great deal to say about the other minor characters of the dialogue. She notes an interesting convergence between the characters of the first book of Republic and the introduction to Parmenides: we have the very same Glaucon and Adeimantus, and a different Cephalus (Meinwald 2005: 12). Whereas the Cephalus of Republic is unphilosophical and conventional, the Cephalus of Parmenides travels to Athens hoping to hear a second- or third-hand account of one of Socrates' discussionsindeed, one substantially more challenging than the one from which Republic's Cephalus removed himself. This odd but apparently insignificant contrast is made more tempting an interpretive feature when Antiphon is introduced. The Antiphon which Glaucon, Adeimantus, and Cephalus visit 'paid a lot of attention to philosophy in his youth' (Meinwald 2005: 13), but now tends to horses as his grandfather, with whom he shares a name, did. As Meinwald puts it, this raises the question as to whether the sharing of names indicates the sharing of natures. This is central to Parmenides; the thrust of the deductions, as Meinwald understands them, is to answer a parallel question: is Large large in the same way the Empire State Building is large? That is to say, do objects that seem to share linguistic features share ontological features as well? Meinwald's reading, it seems, is capable of explaining the importance of perhaps all of the most minor characters of the dialogue: Glaucon, Adeimantus, Antiphon, Cephalus, and Aristoteles.

Further, the stylistic structure of the second part of Parmenides seems as if it fits with Meinwald's account. As I noted in the first chapter, the narrative frame completely 
disappears in the dialogue between Parmenides and Aristoteles. While it is usually the case that in Plato reported speech is interspersed with 'he said' occasionally, in Parmenides, our narrator is almost entirely absent. Meinwald has argued that this increases the immediacy of the second part of the dialogue, and makes it easier to be drawn into the Parmenides' exercise. Given that we are motivated to make the pros distinction by the apparent contradictions between Parmenides' hypotheses, the disappearance of the narrator forces us to try to follow Parmenides' reasoning more closely, as well as see why Aristoteles answers as he does. Thus, the disappearance of indirect discourse in the second part of Parmenides helps to reinforce the general project to have the reader, and Socrates, develop Meinwald's account of predication. It seems Meinwald's interpretation has little difficulty with the structural and literary elements of Parmenides.

The gymnastic approach initially has some difficulty explaining Parmenides' choice of topics for the deductions. Meinwald argues that 'the negative results of the first deduction...are clearly special to the choice of subject' (Meinwald forthcoming: 17). One of the major objections that tend to be marshaled against the gymnastic approach is that it is unclear why all of the results of the apparently pros heauto deductions are negative ones; it would seem that this implies that the One has no properties at all. As a result, it seems somewhat strange to some, Gill among them, that these are apparently definitional properties. Meinwald seems to affirm this, claiming that if we were to pick a different subject, like 'an Animal, a Letter, a Virtue, a Geometric form' (ibid.) and so on, we would find that they do indeed have further pros heauto qualities, thus dodging Gill's question. This, though, seems problematic; why would Parmenides choose a subject that 
makes his primary innovation for Socrates' training a unique form that is more problematic than the rest? This seems to make Parmenides' point more obscure. If the connection between the first and the second parts of the dialogue is that the pros distinction lets Socrates solve Parmenides' objections, then it seems odd that he would choose to discuss a subject that communicates this distinction less intuitively than any alternative. Further, this runs counter to what Parmenides implies when he is selecting the subject. With great reluctance, and after a substantial amount of pleading from Socrates and Zeno, Parmenides relents and agrees to give a demonstration of the training he has prescribed to Socrates. However, since he is being forced to play such a 'strenuous game', he asks to be allowed to 'begin with [himself] and [his] own hypothesis' (137b), that it is one. Thus, Parmenides seems to suggest the one not because it is a special metaphysical case, but instead because it is easier. Meinwald's reading would have us think that the one is indeed the most difficult subject of such exercise.

To this, Meinwald's position can reasonably be extended to give two responses. First, for Parmenides, the exercise with the subject of the one would indeed plausibly be the easiest. As he says, it is his own hypothesis; it is not a stretch to suggest that it would be the argument with which he is most familiar. Thus, though for the reader, Socrates, and Aristoteles, this is an especially strenuous exercise, the claim that this is the least difficult for Parmenides is not clearly false. There is evidence to suggest that Parmenides would expect Socrates to pick up on his implication regardless, as he compliments Socrates on his special skill and passion with regards to philosophy. Second, Meinwald could make the claim that though the entirely negative pros heauto deductions have been 
among the most troubling features of the dialogue for interpreters, ${ }^{41}$ it would be difficult to pick out the distinction Parmenides is trying to make without being spurred on by apparently problematic conclusions. Indeed, the contrast between pros ta alla and pros heauto predication is made especially clear by the choice of the one as a subject. She points out that '[m]ost other forms are not so important that if we consider their participants after abstracting in thought the relation to those forms we destroy their participants as viable subjects. It won't turn out in those cases that if these forms are not, then nothing is anything' (Meinwald forthcoming: 18). Just as Aristoteles reacts with skepticism to the first set of deductions before coming to understand what Parmenides is getting at by the eighth, the reader could plausibly be claimed to be better spurred towards understanding by such bald contradiction as the claim that the one is both nothing at all and everything. Thus, Meinwald's thesis is capable of dealing with Parmenides' choice of subject.

This reading is also capable of explaining the structure of Parmenides' deductive project, as well as the content of his instructions. As noted in the previous chapter, there are eight deductive sets with an appendix to the first two appearing between the second and third. ${ }^{42}$ Read with the pros phrases in mind, they seem to do what Parmenides suggests Socrates must do. He must hypothesize not just his positive thesis, but also its negation, and derive the exhaustive set of consequences: self-self, self-other, other-self,

\footnotetext{
${ }^{41}$ Take, for example, M. L. Gill, who actually takes the fact that the apparently pros heauto deductions are entirely negative to be a strong objection to Meinwald's view (Gill forthcoming: 10).

${ }^{42}$ One could object here that the appendix on time is not forecasted by Meinwald's reading, and this is true. However, given the general structure of Meinwald's solutions to the problems of Parmenides' second section, in that she looks to dissolve the apparent contradictions, it would seem that that appendix makes sense in that it makes explicit the unproblematic nature of intradeduction contradictions. However, she must here concede that a reading of the instructions for the exercise that can not only explain the appearance of the appendix but further forecast it is the stronger reading in this case.
} 
and other-other. Thus, there are four deductive sets for each of the two starting points, the hypothesis and its negation, and they pursue different types of consequences. Indeed, her reading can even account for Socrates' confused reaction: this kind of reasoning initially seems somewhat redundant if we 'don't yet know the force of the in-relation-to qualifications' (Meinwald forthcoming: 5).

By way of summary, let us see in brief what the gymnastic approach's answers to the questions from the previous chapter are. Let us begin with the structural and literary questions. First, it seems that we could argue that the reason that the conversation between Parmenides and Socrates is important enough to motivate Cephalus to make a trip to Athens decades later in order to hear a third-hand account of it is either that (a) the one is an arche and thus has fundamental ontological significance ${ }^{43}$ or (b) the pros distinction is vitally important for the practice of philosophy. It is not clear to me that either of these answers are especially compelling; the fact that this conversation is memorized rote by two non-philosophers seems to suggest that its significance should be of more general appeal than fine-grained distinctions about predication. We will examine this question in more detail in the next chapter. That said, it seems that Meinwald's reading can capably answer my question about the disappearing narrative frame in the second part of the dialogue. She argues that this has two related effects: it increases the immediacy with which we interact with the second part of the dialogue, and as a result forces us to engage in the exercise that Parmenides prescribes to Socrates (Meinwald 2005: 18). Second, Meinwald can argue that the connection between the two major parts

\footnotetext{
${ }^{43}$ I gesture towards this as a possibility for charity's sake, but we will be examining it in more detail in chapter three.
} 
of the dialogue is that the problems of the first are solved by the upshot of the second; by coming to understand the pros distinction, Socrates can defeat the objections Parmenides has marshaled against him. Third, she assigns some significance to every character present in the dialogue including those that are apparently quite minor, ${ }^{44}$ and can show why it is that Aristoteles changes his mind during the second portion of Parmenides. If Aristotles is meant to come to an understanding of a particular type of predication in the process of his conversation with Parmenides, then it makes sense that he does not understand the conclusion of the first hypothesis and objects to it, but is amenable to the summaries at the end of the fourth and eighth hypotheses. Fourth, Meinwald has argued that the reason Parmenides responds differently to Socrates' aporia than is usual for Socrates' reactions to his interlocutors is to make clear a distinction between their pedagogical methods, and demonstrate to what extent there is 'something inherently problematic in the way Socrates' treats people (Meinwald 2005: 16); that is to say, it tends not to be a particularly effective teaching method to embarrass someone in front of a large crowd of people, especially attractive youths.

The gymnastic approach seems best suited, though, for what I have called the argumentative elements of Parmenides. First, she argues that the apparent contradictions between Parmenides' deductions are the primary motivating force for causing Aristoteles, Socrates, and the reader to develop a notion of the difference between pros heauto and pros ta alla; if it were not the case that the deductions on their face were apparently in direct an obvious contradiction, we would not be inclined to try to resolve the tensions and as a result come to the pros distinction. Second, Meinwald's account seems

\footnotetext{
${ }^{44}$ Meinwald (2005) is devoted almost entirely to this task.
} 
thoroughly to parse Parmenides' instructions; as she puts it, the core of her argument is based on what it is that makes Parmenides' methodological remarks so stilted and stylistically awkward: the relational qualifiers. However, as I will argue in more detail in the remainder of this chapter, it is not clear she makes any use of the force of Parmenides' claim that Socrates should 'hypothesize'. That being said, the gymnastic account's claim that we come to understand the pros distinction via 'homework' of how it is we come to understand the pros distinction seems consistent with Parmenides' dialogue with Aristoteles conceived of as an exercise. Third, Meinwald, though acknowledging that Parmenides' objections to Socrates are not fatal, would deny the claim that Parmenides does not give Socrates the way out of the argument. Instead, by helping him to develop the correct account of predication, Parmenides gives to Socrates the tools necessary in order to answer his objections, though not precisely how to apply those tools. Fourth, we can take Parmenides' conclusion at face value, as long as we keep relationality in mind. That is to say, it seems that Parmenides has simply deduced a number of consequences of the one's existence, including some of its properties. In cases where it seems like embodying these properties is logically impossible, we must remember that the display of $F$ and having $F$ as part of an account are different ways of being $F$.

Lastly, we must examine the questions involving other dialogues and other thinkers. As I have noted, these questions are necessarily more speculative, and few authors directly address more than possible links with other dialogues; as a result, we should not discard an interpretation solely on the basis of it not having a great deal to say in response to these queries. First, Meinwald argues that Parmenides' methodological 
remarks and example forecast 'the genus-species structures of the Phaedrus, Philebus, and Statesman', and is derived from 'the kath' heauto/pros allo distinction of the Sophist' (Meinwald 2005: 12). That is to say, by developing the pros distinction, Plato comes to a system of conceptual analysis with which he can more easily break down what it is to be $F$, and makes use of it in other dialogues. ${ }^{45}$ Second, Sayre (1996) has objected to Meinwald that this sort of genus-species relationship seems much more like Aristotle than Plato. If we are looking for possible links between the two thinkers, then this may count as some evidence in favour of the gymnastic account of Parmenides, as well as Sophist, Phaedrus, Philebus, and Statesman. Though this would be a necessarily speculative claim, Plato having what looks like a less developed version of Aristotle's favourite system of reasoning speaks to the possibility of the influence of Parmenides on later thinkers, and may attest to the accuracy of Meinwald's reading. Third, it is unclear how the pros account of Parmenides bears much of a relationship to the historical Parmenides, as it makes no special claims about the topic of the second part of the dialogue aside from pointing out that it makes the apparent contradictions that spur us towards the development of the pros distinctions more stark. It seems, then, that on a brief review of our heuristic, Meinwald's reading does quite well, though there are clear deficiencies.

\section{3: Objections to Meinwald}

There are certain objections generally raised in response to Meinwald's reading. The first problem is the claim, common to both Rickless (2007) and Gill (forthcoming), that her

\footnotetext{
${ }^{45}$ Meinwald argues that the genus/species trees of Philebus, for example, are an articulation of pros heauto natures, starting from the highest level of abstraction, and moving down. The Mammal is $x$ pros heauto; the Cat is $x$ and $y$ pros heauto, and so on and so forth.
} 
central thesis about the importance of the pros constructions is unsupported by Parmenides, and indeed at certain times directly contradicted by it. Second, though pros heauto and pros ta alla appear in other texts, they do not seem to be used in the highly technical sense for which Meinwald argues. Finally, I will return to what I take to be the weakest textual points of Meinwald's reading: her accounts of Parmenides' methodological remarks and of the importance of the conversation of Parmenides. These points are related to the major modification I think is necessary to her reading: we must take seriously Parmenides' assertion that Socrates must not just posit $x$ and not- $x$ and derive systematic consequences for each, but that he hypothesize, and that this is importantly different from mere positing.

Gill articulates the objection for the under-determination of the pros hypothesis in Parmenides by referencing two passages. First, Meinwald's reading is committed to the claim that each set considers either pros heauto consequences or pros ta alla consequences. However, it is not immediately clear that this is the case; in the sixth deduction, for example, 'Parmenides considers relation to self and others in the same deduction' (Gill forthcoming: 9), by arguing that the one 'would have neither likeness nor difference in kind in relation to itself or in relation to the others' (164a). There is a similar problem in the third deduction, where Parmenides produces the consequences of 'the one is' for the others in relation to the one and 'in virtue of themselves' (Gill forthcoming: 12), which sounds similar to pros ta alla and pros heauto. ${ }^{46}$ Thus, it seems that Meinwald's pros phrases are not evenly distributed through the second part of the

\footnotetext{
${ }^{46}$ It is worth noting here that the final clause is not a pros heauto construction, but instead is auto kath' hauto, a phrase that to Gill seems to mean the same thing.
} 
dialogue. Though the places in which Parmenides seems not to meet Meinwald's claims are few, if the pros distinctions are central to the content of the dialogue, then we would expect to find no errors at all on such an important point. Even if the text is mostly faithful on this point, it is troubling for Meinwald's reading to find inconsistencies regarding the arrangement of pros hypotheses. Sandra Peterson (2003) has tried to solve this problem by suggesting that the basic insight of Meinwald's pros hypothesis is correct, but that it does not map on to the dialogue perfectly. That is to say, some deductions do address both pros heauto and pros ta alla consequences, but that simply means that the pros phrases do not structure the arguments; it does not follow from this that they do not have the technical meaning Meinwald attributes to them.

This may be weakening the importance of the pros constructions too much for them to be useful anymore, though. Recall that one of the primary advantages to accepting the pros heauto/pros ta alla distinction is that it helps us resolve the apparent contradictions. The one can be $x$ and not-x, if it is not-x pros heauto and $x$ pros ta alla. However, this construction does not appear sufficiently often in the text to help us make this distinction if we do not assume that each deduction is structured around a certain type of predication, and take that assumption from Parmenides' articulation of his method. If the pros constructions do not apply consistently to each deductive set, and the methodological remarks do not sufficiently determine that each set is either pros heauto or pros ta alla, then we can no longer resolve the inter-deduction contradictions, and we may go so far as to lose one of the primary lessons that Meinwald suggests we learn from Parmenides. There are two possible responses to this objection. First, the evidence Gill uses seems as if it actually tells against her conclusion. As I noted above, the pros 
constructions do not appear very often in Parmenides' example, even though they are prominent in his instructions; this is something Gill notes, too. It is an unusual event in the deductions themselves to have Parmenides' say ' $x$ is $y$ pros heauto'. The fact that Parmenides does use these constructions next to each other in the sixth deduction does not necessarily militate against Meinwald's claim; it would only do so were this a regular occurrence. As this is an anomalous way to phrase the deduction, we can reply for Meinwald that this is thus an anomaly; Parmenides uses the pros phrases here to make clear what he is saying, because in most other cases the type of predication occurring is implied by the methodological remarks that structure his deductions. If this is, as Peterson says, a rare case that goes against the general trend Meinwald predicts, then it makes perfect sense to have Plato mark it out with the explicit employment of the pros phrases. The second option is that Parmenides is making a reference to the fifth deduction when he makes his pros ta alla claim. In the fifth deduction, he has proven the relationship between likeness and equality (161e); he is as a result justified in saying that because the one has 'neither largeness nor smallness nor equality' (164a) it does not have likeness or difference in relation to the others, because he concluded this in the previous deductive set. This, then, does not have to be a troubling objection.

The second objection is also leveled against Meinwald by Gill. In Sophist, pros heauto and auto kath' auto are both used. Recall that auto kath' auto, for Gill, means what Meinwald means when she says pros heauto. In Sophist, pros heauto is used as well; however, it does not mean in Gill's estimation that 'a property the subject has in virtue of itself or by definition', but instead it simply indicates that 'the subject has the property under discussion as a matter of relation to itself'. The claim that ' $[c]$ hange is the 
same in relation to itself [pros heauto]' simply means that 'change is identical with itself' (Gill forthcoming: 9). In conjunction with this claim about Sophist, Gill flatly asserts that the pros phrases mean nothing aside from 'in relation to $x$ ', as opposed to having any technical meaning.

This may well be true, but let us consider two objections. First, though the terminology of Sophist is clearly not irrelevant to the interpretation of Parmenides, Meinwald's claim is that this particular distinction in types of predication is an innovation, not something that Plato is working with throughout his corpus. Though Meinwald and Gill will both say that Sophist was written after Parmenides, the employment of different language does not necessarily change the conceptual distinction. As a result, even if we were instead to be agnostic about the compositional order of the dialogues, having Parmenides come after Sophist would be unproblematic. The fact that there exists a similar distinction in Sophist-which indeed seems to work in favour of Meinwald's claim-even if it is expressed differently, does not seem to provide good reason to abandon the pros distinction in Parmenides. That being said, the motivation for this objection is a good one; we ought not make the account more complex than absolutely necessary, especially when it seems a simpler option exists.

I think the second reason to think Meinwald is correct may be more convincing. We have to remember that Parmenides does not volunteer to provide an example of his method; Socrates and Zeno have to beg for one. This suggests that there is something complex about the method that requires a great deal of clarification. If we understand pros heauto non-technically, we are left with a dual problem. On one hand, it is not clear what it is that makes Parmenides' instructions obscure enough that Socrates must ask for 
clarification; on the other hand, why is it that pros heauto requires no clarification in Sophist, but requires such an extensive example in Parmenides? The best solution to both these problems is to hold that instances of pros heauto in Sophist and Parmenides do not necessarily have the same meaning.

On review of our heuristic, we must note that there are two major points on which the gymnastic account reading seems to be silent. First, though Meinwald's account puts a great deal of weight on the methodological remarks that forecast the deductions of the second part of the dialogue, she understands Parmenides' assertion that Socrates should hypothesize to be non-technical. That is to say, her reading of the second part of Parmenides does not have anything to say about the nature of hypothesizing. In the next chapter, I will contend that it means more than simply to posit, and that this becomes clear when we pay attention to Plato's discussion of hypothesis in Meno, Phaedo, and Republic. Second, Meinwald is unable to marshal a convincing answer to what it is that makes the discussion in Parmenides so important that at least three people-two of which were not present at the conversation-have committed it to memory, and that it motivated Cephalus to make the trip to Athens in hopes of having it recounted to him. Though it may well be the case that the pros distinction is central to Plato's ontology and logic, it is unclear that this would be enough to have the characters of Parmenides accord the dialogue such importance. I believe this question and the first are related, and I will make this case in the next chapter. ${ }^{47}$ There are, further, some less central points that

\footnotetext{
${ }^{47}$ In short, if proper use of hypothesis is what separates philosophers from mere mathematicians as Socrates suggests in Republic, then Parmenides' instructions to Socrates may well be of some importance.
} 
Meinwald's reading as presented here seems unable to account for satisfactorily, but these will become clear in contrast with Gill's reading in the next section.

\section{3: Gill, Rickless, and the Metaphysicalist Reading of Parmenides}

The primary thrust of the metaphysicalist position on Parmenides is that Parmenides gives an argument that demonstrates some sort of metaphysical innovation. That is to say, there is positive theoretical content that is the direct result of the argumentation of the second part of the dialogue. This alone, though, does not distinguish this school from Meinwald; they also make the negative claims that (a) there is no significant methodological innovation in Parmenides and (b) that we access the positive metaphysical innovation not through some sort of logical training, but instead as we would in any other dialogue: by an examination of the arguments. The first thing to note is that the differences between the conclusions of Gill's and Meinwald's arguments are slight at best; the major distinction in the modern debate is instead how we ground the conclusions of the separate camps. In order to generate the most plausible reading for this, I will build primarily off of Gill's forthcoming paper that is a restatement and modification of her thesis from her earlier Parmenides (1996), and use Rickless' (2007) work to improve clarity and precision.

Gill argues for three central claims as the primary thrust of Parmenides. First, she claims that Parmenides' deductions are a proof of the existence of forms 'since there is a world to explain' (Gill forthcoming: 2 ); ${ }^{48}$ second, she argues that that 'the one must partake of natures other than its own, including its own opposite' (ibid); finally, in order

\footnotetext{
${ }^{48}$ This follows from the indirect proof at the transitional passage. Parmenides claims that without forms, dialegesthai [conversation, dialectic] is impossible. Given that the passage is surrounded by instances of dialectic, it seems that we can conclude by denying the consequent that there must be forms.
} 
to avoid a dilemma that she argues is presented by the conjunction of the first and second deductive sets, she claims that each form 'explains its own immanent character' (Gill forthcoming: 22) and that 'being is inside the nature of beings' (Gill forthcoming: 21). Thus, we can condense her claims about the primary arguments of Parmenides to the following list:

(1) There are forms.

(2) Forms have immanent characters; they all have being inside themselves, and they all have their own property by partaking in themselves.

(3) Forms partake in their own opposites.

There are two points to note immediately. First, these conclusions do not drastically differ from Meinwald's in many respects. Though Meinwald does not outright state (1) as an interesting conclusion of Parmenides, it is clear that she is committed to it. Much of assertion (2) is contained in Meinwald's theory as well; the way she explains pros heauto predication implies that the Large is in some way large with reference to itself. It is on (3) that Gill and Meinwald differ enormously; Meinwald sees no reason to posit that forms must partake in their own opposites, while Gill suggests that this is necessary in order to explain certain parts of the dialogue. In parallel, Gill makes no claim about the one being a first principle for Plato. Second, careful readers of Rickless (2007) will notice that he makes not only the claim in (3), but also argues that Socrates has to abandon the following claims about the forms (Rickless 2007: 240):

(a) Purity-For any property $F$ that admits a contrary of $F$, the form of $F$ is not con- $F$

(b) Uniqueness-For any property $F$, there is exactly one form of $F$-ness 
I have two reasons not to include these claims in my characterization of a general metaphysical position. First, this an argument no other commentator makes, though this may well be a result of just how close attention Rickless pays to the logical structure of the arguments of Parmenides. As a result, any attempt to synthesize his work into a broader position seems as if it tempts some compromise with the other authors in his camp. Second, and more importantly, Rickless admits that while Plato drops principles (2) and (3) in other dialogues, he continues to use principles (a) and (b) (ibid). This seems to suggest, independently of the rigour of Rickless' analysis, that Plato does not intend to abandon principles (a) and (b) due to Parmenides' arguments. As a result, it seems that the stronger metaphysicalist position is that which does not commit to all of Rickless' claims, but only that Socrates must grant (3). Additionally, it is worth noting that Rickless does not argue for Socrates having to accept (2); this same problem is solved in his work by having Socrates abandon (b). Given that Socrates seems to use (b) in later texts, but does allow for self-predication, it seems to me that the better solution is Gill's.

Gill opens her analysis with the claim that the second part of Parmenides is a single argument 'designed to provoke the student to find a way to save the positive hypothesis that the one is' (Gill forthcoming: 6), as if something is, the One must be. ${ }^{49}$ We are meant to be spurred by the apparent problems in the dialogue to try to see what premises we can change to avoid Parmenides' conclusions. The first problem that is to motivate us appear at the end of the first deduction, where Parmenides concludes that if the one is strictly one, then it does not exist; 'the one cannot be one without partaking of

\footnotetext{
${ }^{49} C f$. The end of the eighth deduction.
} 
being, a feature different from its oneness, to link it to its oneness' (Gill forthcoming: 19). That is to say, by Parmenides' reasoning, the one cannot exist unless it participates in its contrary property: manyness. Gill grounds this by arguing that deductions one and two actually treat slightly different hypotheses, and that the first treats the one as a monadic unity. If, however, the hypothesized one as a monadic unity cannot exist, we must modify the thesis, as Parmenides invites Aristoteles to do at the conclusion of the first deduction. Thus, Parmenides rescues the existence of the one in the second deduction by weakening Socrates' principle, stated in the first part, that he would be amazed if Parmenides could demonstrate that one is many, or many is one (129b). As such, Parmenides posits the different, second hypothesis in which the one is 'a relational property linking the subject to its own or other properties' (Gill forthcoming: 18). That is to say, in the second deduction, the one is allowed to partake in being so that it can be one; otherwise, it cannot be at all. However, as the one has two properties now, it seems to be many. And in fact, this consequence is derived throughout the rest of the second deduction, which shows that 'the one turns out to be both one and unlimited in multitude' (Gill forthcoming: 19) and that it is 'both $F$ and not- $F$ ' (ibid) for the same properties in which it could not participate in the first deduction. As Gill summarizes the second part, it produces a dilemma: 'if the one is one...the one is nothing' (Gill forthcoming: 20), because it cannot exist; 'if the one is not...there is nothing at all' (ibid), as demonstrated at the end of the eighth deduction. If we want to maintain that something exists, then, and deny the consequent of the second conditional, we are forced to claim that the one exists. The only way the one can exist, though, is if we 'admit that the one is both one and many' (ibid). 
This is the solution to the first problem with which we are presented in Gill's view: given the choices that the one either exists or does not, we are forced to choose that the one exists. If it exists, though, it must be many, and Parmenides has suggested that the consequence of its manyness is that 'the one is everything' (ibid). In order to salvage the existence of the one, and thus the existence of anything at all, we have to look closely at the second deduction, in which Parmenides has shown us that allowing the one to participate in many has it be everything. Gill suggests that by denying 'that being is a nature outside the nature of beings' (ibid), we can avoid the unpleasant consequences of the second deduction. That is to say, to save the claim that the one is, we have to argue that its being is an immanent property. If we do so, then we no longer have to claim that the one is everything, because it no longer partakes in something else, due to being's status as a part of its nature. This, then, demonstrates Gill's second claim: forms can have immanent characters, and one of those immanent characters must be being.

Generating Gill's third claim is a little more difficult, and to do so we must rely on Rickless. First, though, it has to be made clear to what extent Rickless and Gill are saying the same thing. Gill's third claim is that Socrates must abandon the premise that forms cannot partake in their contraries. I take Rickless' equivalent argument to be his claim that the principle of Radical Plurality, the principle that no form can have contrary properties, should be abandoned (Rickless 2007: 186).$^{50}$ Rickless argues that there are a number of reasons to abandon Radical Plurality. First, consider the consequences of deductions two, three, and four. They all imply that if the one is, then it must participate

\footnotetext{
${ }^{50}$ Rickless argues that Plato is committed to a principle of causality such that for any property $F$, all $F$ things have property $F$ by virtue of partaking in the form of $F$. By combining this principle with Radical Plurality, we can get Gill's third claim.
} 
in its contrary. Deduction two has as a sub-conclusion that if the one is, 'the one itself, chopped up by being, is many and unlimited in multitude' (Parmenides 144e); deduction three suggests that 'the others are not absolutely deprived of the one, but somehow partake of it' if the one is (157c); at the end of deduction four, Parmenides argues that 'if the one is, the one is all things and is not even one' (160b). It seems that Parmenides gives good reason to reject Radical Plurality on his own, as in all of these cases, the one seems in at least some way to partake in the many. If the one is, and if other forms are, then the one necessarily partakes in the many.

If we grant her assertions, then, Gill is capable of answering many of the problems for the interpretation of Parmenides. First, she can explain the link between the two major portions of the dialogue in much the same way that Meinwald does. In the first part, Socrates is left with a number of objections to his notion of the forms, and they can be resolved by the lessons of the second part. If a form "has its own character in virtue of itself', then a Largeness regress is no longer a problem; it does not need another large entity to explain its own magnitude. Further, Gill argues that Parmenides' demonstration answers what she takes to be a challenge from Socrates. Socrates, at the start of engagement with Zeno, makes the claim that Zeno is supporting Parmenides' philosophy indirectly; that is, he takes Zeno and Parmenides to be making the same argument. Part of his response to Zeno is that he is unimpressed by the claims that sensibles have contrary properties, and that that claim is uninteresting unless forms, themselves by themselves, do so as well (129b). If we take this as a challenge issued to the Eleatic position, then in conjunction with the fact that Parmenides takes up his own hypothesis, we may be justified in concluding that Parmenides is responding to Socrates' challenge. Parmenides' 
argument that Socrates must abandon Radical Plurality also solves what Rickless claims is the heart of Parmenides' objections in the first part of the dialogue: Parmenides' dilemma for Socrates as to whether sensibles partake in a whole or in a part of forms is only a problem if forms cannot partake in their contraries (Rickless 2007: 57; 60).

Gill is also capable of dealing with the apparent contradictions between deductions, but does so in a way that she is not then further tasked to make the entire second section sound. Instead, she has made the claim that they are intentionally unsound, and that we are meant to identify premises that cause the argument to go offtrack. This has the further virtue of preserving Parmenides' claim to be training Socrates, in that he is forced to exercise himself, go over the deductions, and see what assumptions lead to problematic conclusions.

Though Gill herself does not write a great deal about the structural and literary elements of the dialogue, M. Miller and K. Sayre, and R. E. Allen can be used to reinforce her account on these points. Miller argues that the reader 'can hardly miss the parallels' with Republic in Parmenides (Miller 1985: 18), referring to the same evidence Meinwald marshals in order to make her arguments about the gymnastic nature of the latter. Miller, however, draws a different conclusion; he makes the claim that ' $[\mathrm{b}]$ oth works are centrally concerned with [the] teaching of forms and participation' (ibid). That is to say, because Republic is concerned with the forms, and the cast of characters and setting of Parmenides recalls Republic, we have some reason to think that the point at issue here is the forms and their relation to sensible objects. This helps to explain those characters that are shared with Republic, and we can turn to Sayre in order to support 
Gill's reading from the employment of Parmenides and Zeno. Given that Plato shows a great deal of respect to Parmenides in other dialogues, Sayre suggests that he is a fitting figure in Plato's eyes to display 'the major ontological innovations' (Sayre 1996: 59) that come out of the second part of Parmenides. Indeed, the type of innovation that the metaphysicalist attributes to Parmenides seems a better fit to the historical figure, and as a result the character, than Meinwald's claim. Parmenides' major innovation seems to be an ontological one. Parmenides does not seem to be responsible for a revolution in predication, but instead is instrumental in the turn to the non-visible realm. Miller (1995) suggests that this is reflected in the way in which the text is composed. He argues of the deductions that 'their densely conceptual language, the absence of imagery and of value terms, and the way in which almost every thesis is both compounded by its contrary and canceled by its contradictory' (Miller 1995: 592) contributes to the need to 'discover a deeper level of meaning' (ibid). Note the similarity to the gymnastic claim, here, that the difficulty of the dialogue is designed to help us to develop an important conceptual distinction. The account of the linguistic and structural elements that Miller gives, then, is marshaled in support of the claim that Parmenides wants Socrates to cut through the obscurity of the deductions as such and instead discover the more fundamental ontological insight.

Again by way of review, let us compare our characterization of the metaphysicalist account to our heuristic, and see how it measures up. As before, we will start with the structural and stylistic elements of Parmenides. First, and again as before, it seems to be the case that Gill's reading has difficulty explaining the significance of the conversation in the dialogue such that Cephalus comes to Athens years later to witness it. 
Recall that our metaphysicalist reading defends three main claims: (1) that there are forms, ${ }^{51}$ (2) that forms self-predicate, and (3) that forms partake in their contraries. Unless the proof for the existence of forms, which is simple and is given in passing, is taken to be of some great importance for Cephalus, it is not clear how any of these technical ontological claims could plausibly be memorized by two non-philosophers as well as of such great interest to someone that he would make the journey to Athens so many years later. That said, the metaphysicalist reading advanced by Gill can make use of the disappearance of indirect discourse in much the same way that Meinwald does. The strategy that Plato is meant to have used in Parmenides to get the reader to come to Gill's three claims is to spur the reader into discovering how to salvage Parmenides' hypotheses by discovering what premises to abandon in his argument; as such, Gill can argue that the reader is meant to take on the role of Aristoteles, and is not to be reminded of the narrative distance between herself and the dialogue. Second, we have argued that the connection between the two parts of the dialogue is that the premises Socrates is forced to reject as a result of Parmenides' hypotheses are the very same premises that, if he were to abandon them, he would be able to salvage the forms. Thus, the second part is indirectly relevant to the problems of the first part, in that they rely on common assertions that must be rejected in order to render either of them coherent. Third, it seems that when it comes to the presence of Parmenides and Zeno, Gill may have a stronger case than Meinwald. If Gill is right, and the central claims of Parmenides are fundamentally ontological in nature, then it seems like this is a better fit with Plato's general treatment of Parmenides, and to a lesser extent, Zeno. Parmenides is treated as the a major

\footnotetext{
${ }^{51}$ Again, recall Parmenides' argument that dialegesthai requires forms at the transitional passage.
} 
influence on Plato's own ontology in Sophist, and putting the metaphysical innovations that can salvage the forms in his mouth as a result makes some sense. ${ }^{52}$ On the minor characters, though, Gill must generally give the same answers Meinwald will, though for different reasons: Glaucon, Adeimantus, and Cephalus are present in Parmenides to recall the conversation of Republic, and thus make central the importance of the forms. Gill runs into some trouble, though, trying to explain why it is that Aristoteles changes his mind in the middle of the second part of the dialogue. Indeed, given that she uses as evidence for her general approach - that we are meant to find and reject certain key premises-that Aristoteles objects to the conclusion of the first deduction, and gives us license to do the same, it seems like a serious flaw in her account that Aristoteles no longer rejects any conclusions by the end of the dialogue, or indeed half way through Parmenides' exercise. I will discuss this in more detail in the next section. Finally, Gill suggests that Parmenides is seeking to salvage Socrates' account of the forms; this project explains his reaction to the aporia at the transitional part of the dialogue.

So much, then, for structural features, as we move on to argumentative ones. First, Gill has a similar sort of answer when it comes to the significance of the contradictions in Parmenides. Though she argues that those contradictions are real, they have the same sort of productive use the apparent contradictions have in Meinwald's reading: they spur us to make a distinction, or in Gill's case choose to abandon certain premises, that are the philosophical upshot of the dialogue. Second, Gill seems thoroughly to parse

\footnotetext{
${ }^{52}$ To a certain extent, this claim is counter-intuitive, especially as the Eleatic Stranger in Sophist suggests that we must commit a parricide against Parmenides in order to straighten out our ontology. However, calling this act 'parricide' implies that Parmenides' theories are part of the lineage of the ones proposed in Sophist.
} 
Parmenides' methodological remarks, especially as she takes into account Parmenides' claim that Socrates should reason like Zeno. However, as I will discuss in the next section, it is not clear that Gill's account of Parmenides' methodology matches up with his example in the second part of the dialogue. Third, as the modern discourse blurs the line between the gymnastic and metaphysicalist accounts, Gill can consistently commit to the claim that Parmenides seeks to exercise Socrates due to what seem to be apparent pedagogical benefits over simply articulating the premises that need to be abandoned in order to salvage the forms. Finally, Parmenides concludes with a contradiction at the end of the dialogue, but it is proven on the basis of false assumptions; he proves that the negative hypothesis, that the one is not, is untenable, while at the same time showing that the positive one apparently is as well.

The strength of this account is its ability to link up with the rest of Plato's dialogues. Gill claims that the exercise that Parmenides centres around the One in Parmenides is continued in Theaetetus and Sophist, where Plato performs the same kind of analysis on Being (Gill forthcoming: 22-23). In the other direction, Rickless (2007) argues that the theory of forms put forward by Socrates in the first section of the dialogue is that theory which is present in Phaedo and Republic. Thus, the metaphysicalist reading can position Parmenides in a distinct phase of Platonic philosophy. ${ }^{53}$ This clearly causes some difficulty with narrative consistency; given that Socrates is young in Parmenides and near death in Phaedo, if we take Rickless' argument that the theory of forms he puts forward in Parmenides is both (a) the same as the one in Phaedo and (b) is improved by

\footnotetext{
${ }^{53}$ Julia Annas has written an essay problematizing this way of situating Parmenides; cf. Annas (2002) pp. 1-24.
} 
Parmenides' exercise, then it is not obvious why Socrates espouses the theory that he does on his deathbed, as he apparently has access to an improved one. Further, the metaphysicalist account does little to link Plato with other thinkers. ${ }^{54}$ Indeed, it is a puzzle for a metaphysicalist reader that Aristotle articulates in Metaphysics some objections similar to the ones given in Parmenides, including the infamous Third Man, as it would seem that if Plato had modified his account such that it avoided this type of regress, Aristotle would be aware of it. ${ }^{55}$ Finally, this account does seem to have some benefit in its link to the historical Parmenides. Recall that in order to solve what she sees as the dilemma of the second hypothesis, Gill makes the argument that we must abandon the claim that the One partakes in a distinct Being, but instead that being is an immanent property. Interestingly, this is the position the historical Parmenides takes in his proem; he argues that 'it' is 'all full of what is' (B 8.23). Thus, to a certain extent, the metaphysicalist reading lines up with what the historical Parmenides seems to have thought. It is interesting to note on review, then, that in a great many of the cases above, the two interpretations we have reviewed do not differ.

\section{5: Objections to the Metaphysicalist Account}

Gill's account of Parmenides' methodological remarks suffers a number of objections, primarily related to how well her characterization of the method maps on to the actual deductions of the second part of the dialogue. She claims that there are four elements to Parmenides' method: (1) that Socrates 'should adopt the manner of the exercise he heard

\footnotetext{
${ }^{54}$ Aside from Speusippus, as argued by J. M. Dillon (2005), which requires a metaphysicalist account of some sort in order to be true.

${ }^{55}$ It is entirely possible, though, that Aristotle articulates an earlier version of Platonism in order to make the contrast between his theory and that of his teacher starker.
} 
from Zeno' (135d), which Gill reads as meaning that he should engage in a reductio ad absurdum; (2) that the method is designed to assess hypotheses about non-sensible objects; (3) that Socrates must hypothesize both his positive hypothesis and its negation; (4) that Socrates should repeat the exercise, and take some other subject in that repetition. Point three, she claims, is further clarified by Parmenides' remarks regarding the structure of the exercise, that Socrates should derive the now-familiar set of consequences. By way of summary, then, she claims that Socrates must hypothesize both his thesis and its negation, and derive consequences for the subject of his thesis in relation to itself and in relation to others, and the others in relation to themselves and in relation to the subject. This exercise should be repeated on other hypotheses with nonsensible subjects, with the purpose of deriving contradictory consequences from these hypotheses and abandoning the premises that cause them to go off-track. ${ }^{56}$

There are a few problems with this account. As Meinwald rhetorically asks of herself, how would the second part of Parmenides be different if it were not a dialogue, but instead a speech (Meinwald 2005: 19)? It seems that for Gill, the only use of having this sort of exercise be a dialogue is to have the interlocutor pick up on problematic conclusions that the speaker may have missed; however, Aristoteles does no such thing in

\footnotetext{
${ }^{56}$ This bears strong similarity to Scolnicov's (2005) account of Parmenides. He argues that Parmenides' is trying to demonstrate the efficacy of Eleatic styles of argumentation to solve apparent paradoxes and aporias. As an example, he gives Meno's paradox, that we cannot recognize something that we do not already know, but we also cannot learn something that we already know. As a result, it seems that teaching is impossible. He suggests that by applying the Eleatic method Parmenides is demonstrating here, if we find the conclusion unpalatable, we can identify the cause of the problem - our definition of 'knowledge' and redefine the background conditions such that we no longer come to the problematic end. Gill's argument shares the same structure: she claims that this method generates deductions such that if the conclusions are unattractive, we can identify which premises we are meant to abandon, as she claims Socrates must in order to save the forms. This sort of position is also taken by Miller $(1985 ; 1995)$ and Ambuel (2005). Any objections raised against Gill's account of the methodology, then, apply equally well to Scolnicov's, Miller's, and Ambuel's readings of Parmenides.
} 
most cases. If this is not the role of the interlocutor, then it is unclear how she can be helpful to the task, as Gill understands it. Further, we cannot make the claim that the exercise is meant to be helpful to the interlocutor, not to the speaker, as Parmenides suggests by way of trying to help Socrates that he repeats the deductive exercises. If Parmenides selects Aristoteles as his interlocutor instead of Socrates, then it seems that it is Parmenides' role which gains the majority of the benefit; otherwise, Parmenides, given his stated goal is to help Socrates, would have chosen Socrates as his interlocutor. Thus, Gill's understanding of the purpose of Parmenides' method seems not to be able to account for its dialogue form, and as a result does not match the actual deductions as they take place; they are not a long speech by Parmenides, though it is easy to forget this fact.

Meinwald raises an objection against this characterization of the method, too. Recall that one of Gill's objections to Meinwald is a dual claim that (a) pros heauto and pros ta alla have no technical sense, and they are simply used to indicate relational predicates and (b) pros heauto and pros ta alla are not distributed as Meinwald predicts through the deductions. As Gill puts it, 'every deduction considers the subject(s) both in relation to itself/themselves and in relation to other things' (Gill forthcoming: 9). Meinwald notes that if this is true, and we take Gill's account of the method to be the case, it is unclear why Parmenides has eight deductive sets. If each set of deductions discusses both kinds of non-special cases of pros predication, then there should only be four sets. What seems in the method to predict eight sets as opposed to four is that each deduction is meant to address either the subject pros heauto, the subject pros ta alla, the other pros heauto, or the other pros ta alla. If each set addresses both pros heauto and pros ta alla consequences, as Gill suggests, then there should only be four deductions. 
Given that there are eight, it seems that Gill's account of Parmenides' methodology does not accurately predict the actual deductions in the dialogue. ${ }^{57}$

There are further problems with Gill's reading. First, she suggests that Aristoteles' and Parmenides' response to the first deduction is evidence that we are being invited to reject its conclusions (Gill forthcoming: 19). However, this is vulnerable to an objection similar to the one that R. E. Allen marshals against F. M. Cornford's claims that there are numerous subjects at work in Parmenides. Allen argues that given that there are summaries at the end of deductions four and eight that seem to treat the subject of each hypothesis as the same, it is odd to posit that there are actually different subjects. Similarly, it is unclear how Gill can reconcile her claim that we are meant to reject certain conclusions in the second part of Parmenides with the sole piece of structural evidence being Aristoteles' protests against the conclusion of the first deduction when he raises no similar protests at the summaries at the fourth and the eighth. It would seem that he either (a) grows weary with the deductions or (b) changes his mind about precisely how objectionable these conclusions are by the end of the dialogue, as he assents to the final summary-which includes the conclusion of the first deduction-enthusiastically. Gill's approach seems unable to explain Aristoteles' inconsistent answers; while with Meinwald, we can make the argument that Aristoteles objects at the beginning because he does not yet entirely understand what type of predication is at work, but does not object at the middle or end because he comes to understand the meaning of the arguments over time, Gill actually would have to have Aristoteles, if he is to be a useful philosophical

\footnotetext{
${ }^{57}$ This leaves to the side my claims about the importance of hypothesis. See section 2.2 for my discussion of the importance of this part of Parmenides' method.
} 
guide, object more strongly at the end. Gill, after all, claims that the apparently contradictory end of the dialogue spurs us to find premises to reject. If Aristoteles is adept enough to pick this problem up after the first deduction, it is unclear why he is unable to do so for the fourth and the eighth. This is reason to think that we are not meant to reject the conclusions of Parmenides.

\section{6: Taking Stock}

By now, it should be clear that the major mainstream interpretations disagree about very little, though they are often presented as diametrically opposed. They employ similar strategies to explain elements of the text in numerous cases. Both, in exploring the connection between the two major portions of the dialogue, suggest that Parmenides is indeed providing Socrates with the tools to answer his own objections, though the mechanics of their answers to this challenge initially seem as if they are drastically different. Both agree that the major contact points for Parmenides in Plato's corpus are Republic, Sophist, Theaetetus, and Statesman, though I will argue in the next chapter that this is not clearly true. Both agree on the general significance of the Glaucon, Adeimantus, and Cephalus, and differ only slightly on Parmenides and Zeno. Finally, both also make use of the obscurity of the second part of the text to make claims about the indirect nature of Parmenides' exercise. The main point of Parmenides, they will both agree, is to provide Socrates with the tools necessary in order to (a) overcome the objections to the forms and (b) further develop his practice of philosophy in the rest of his life. There are, however, important points of disagreement in the details. 
Using our heuristic, we can see which elements of the text cause the gymnastic and metaphysicalist accounts to be in tension. The first major disagreement is on the logical status of the second part of Parmenides. Meinwald puts forward a way of reading the pros phrases with which she argues we can resolve the apparent contradictions between the deductive sets, and claims that a sensitive reading of those contradictions internal to any particular set reveals that they are not contradictions at all. In contrast, Gill suggests that the arguments do in fact have conclusions that are in conflict, and that this is part of Parmenides' strategy; he intends to have Socrates identify the points at which Parmenides has gone wrong, and reject those premises that cause these problems. I have argued that on this point, Meinwald's position seems to be better in agreement with the text, based primarily on my claim that Aristoteles seems able to pick up on apparent problems during the first deduction, but expresses no skepticism for the rest of the dialogue. Instead, he enthusiastically endorses propositions that certainly seem on their face to be logically impossible. We would expect, if Parmenides were really expressing something dubious, that his interlocutor would pick up on it, even if he is chosen at least partially because he is the least likely to give Parmenides trouble. ${ }^{58}$ Meinwald and Gill further disagree on the importance of Parmenides' claim that Socrates should hypothesize in the manner of Zeno. If we accept, however, that there are no major, intended contradictions in the second part of the dialogue, Gill's reading of the instruction to hypothesize like Zeno no longer has any bite to it.

\footnotetext{
${ }^{58}$ Indeed, it is possible that Parmenides means that Aristoteles will not give trouble in the sense that he will not try to answer 'strategically' to avoid unpalatable conclusions, as the other reason he picks Aristoteles is that he 'would be the most likely to say what he thinks' (137c).
} 
The most important point upon which the two interpreters seem to disagree, though, is what precisely those tools are that help Socrates to overcome the objections to the forms and further to develop his philosophy. While Meinwald focuses on how precisely $x$ can be predicated on $y$, and what ' $x$ is $F$ ' means, Gill analyzes the nature of those properties that are predicated, and those entities that do the predicating. That is, Meinwald investigates the nature of the relationship between entities, whereas Gill works on what those entities that are related are. Put another way, while Gill is concerned with the properties of $x$ and $F$ in the proposition ' $x$ is $F$, Meinwald focuses on the nature of the 'is'.

This brings out an important point about the commensurability of the two mainstream interpretations of Parmenides. Meinwald suggests that we can resolve the problems of the first part of the dialogue by understanding how predication works; she does not deny either that (1) forms can self-predicate or (2) that forms can participate in their opposites. Indeed, her reading relies on the first claim, as $x$ being $F$ pros heauto means that in a sense $x$ has $F$, and $F$ can be the property that $x$ is meant to provide to other entities. That is to say, the Rectangular can be rectangular pros heauto, and in doing so it self-predicates. The second claim, on examination, seems complimentary to Meinwald's theory. Take the proposition 'the Large is small'. If we understand the predication here pros heauto, it means that 'smallness is part of the account of the Large'. As a result, it actually makes a great deal of sense; what it is to be small is actually contained in the account of what it is to be large, as being small is at least partially defined as not being large. This can also be demonstrated pros ta alla with the proposition 'the One is many', as Parmenides himself shows in the second deduction. 
The One must be as a result of others existing, as Parmenides argues at the end of the eighth deduction. Thus, if the others are, the one is and is one. The One then displays manyness pros ta alla, which we must accept if we are to take Parmenides' deductions to be true.

This is not merely an arbitrary combination of positions for the sake of convenience; it actually strengthens Meinwald's account of the dialogue to take on Gill's solution to Socrates' problems. Gill makes a compelling case for taking Socrates' claim that he would be impressed to see that non-sensible objects participate in their opposites as a challenge, which otherwise Meinwald's reading leaves entirely untouched. As noted in section 2.3, Meinwald has some difficulty account for the topic of the deductions, as well; by taking on Gill's remarks about the properties of forms, she dodges this problem. Perhaps more importantly, by taking on the metaphysicalist account, especially on the matter of self-predication, Meinwald's reading can give some clear importance to the presence of Parmenides that otherwise seems like a surprising feature of the text. Further, Gill's account of the solution can be improved by Meinwald's. Vitally for Gill, if we take on Meinwald's account of Parmenides' method, then we no longer have a problem explaining the structure of the exercise in the second part of the dialogue or Aristoteles' change of heart. The biggest distinction between the two positions, then, does not actually put the accounts in opposition at all. It seems that they are not simply compatible, but complimentary.

It seems that we can articulate the combined reading of Parmenides as being committed to the following claims: 
(1) Parmenides' demonstration is meant to show Socrates how to deal with the objections of the first part of the dialogue indirectly; it does not provide an immediately obvious answer.

(2) Parmenides' method establishes a way of thinking about predication that allows for both $x$ is $y$ meaning that $x$ has the property $y$ and $x$ has $y$ as a part of its account.

(3) Parmenides demonstrates that forms can self-predicate and have their opposites predicated on them.

(4) Parmenides accepts that there are forms.

(5) Parmenides accepts that the One is a first principle or unhypothetical starting point. ${ }^{59}$

This combined view has all of the major virtues of the Meinwald- and Gill-inspired positions, as well as including the methodological focus on hypothesis that I have argued improves the explanatory power of any interpretation.

It is important to note a few features of this interpretation. First, it may initially seem strange to take on Gill's claims when they are derived from a premise that I have argued against. That is, if she claims that the way we come to knowledge of the properties of the forms in (3) is by trying to overcome the contradictions in the second part of the dialogue, and there are no contradictions, what reason do we have for believing (3)? There are two answers to this objection. First, self-predication, as I have noted, is built into Meinwald's theory already; the proposition 'the Large is large pros

\footnotetext{
${ }^{59}$ Again, this will be discussed in detail in chapter three; I leave it on this list for the sake of completeness.
} 
heauto' is already a case of self-predication. This part of the conjunct, then, requires no further explanation. The claim that forms can bear a relationship to their opposites is not immediately implied by Meinwald's theory, though. Even if this claim is not ruled out by Meinwald's reading, that is insufficient reason on its own to believe it. However, it is worth noting that Rickless does not take there to be any contradictions in the dialogue either, and he is perfectly capable of generating (3). He does so, as noted above, by claiming that the one can partake in its contrary because (a) it is a consequence of the existence of the one (deductions two, three, and four) and (b) abandoning Radical Plurality contributes to solving almost all of Parmenides' objections.

Meinwald's reading can address these objections, though, without abandoning Radical Plurality, and does so by making two moves. Problems of Radical Plurality occur for Rickless, first, in the generation of regresses, and, second, in the assignment of sensible properties to non-sensible objections. For example, the Third Man that causes problems for Socrates' claims that the forms are patterns in nature assumes that the form of likeness can resemble other like things-and thus be like-only as long as there is another form to give it itself the property of likeness. Since Meinwald allows for selfpredication, this is unnecessary; further, Likeness can be like pros heauto and thus not be required to display the property of likeness. That is to say, a like sensible can resemble Likeness by being like pros ta alla, whereas the form itself can be like pros heauto. Chair $A$ and chair $B$ are not as a matter of definition like each other-part of the account of $A$ is not that it is like $B$-but they are both in relation to the form of likeness. On the other hand, being like is part of the account of likeness. Thus, Meinwald need not abandon Radical Plurality to solve a regress. 
Further, Meinwald can solve the whole-part objection simply by abandoning the superexemplification view of the forms, which we must do in order properly to understand pros heauto predication; if we do not assume that the form of Gold is a sum total of all the gold in the universe, and that in fact it does not display the property of goldness at all, the question as to 'how much' of the gold each golden thing gets no longer makes sense. As such, Meinwald has no reason to accept the claim that forms must partake in their contraries in such a strong form, as that strong form solves none of Parmenides' problems any better than an understanding of what it is to have property $F$ pros heauto. Note too that the claim that we should abandon Radical Plurality due to implications from deductions two and three and the summary at deduction four is not as strong a claim with a reading of the dialogue that accepts the pros distinction. Deductions two and three are pros ta alla deductions, and deduction four sums up their results. Thus, the claim that Meinwald must accept is that forms must partake in their contraries pros ta alla-the one is many in relation to others-but not pros heauto. So, we can change condition three of the combined interpretation to read: Parmenides demonstrates that forms can self-predicate and that they must partake in their contraries pros ta alla.

This solves further problems. As Rickless points out, having Socrates accept both self-predication and the possibility of pros ta alla participation by forms in other forms helps explain his theories in Sophist, Statesman, Theaetetus and Philebus (Rickless 2007: 241). In Sophist the Eleatic Visitor argues that if forms can be known, they must move from having the property of being unknown to the property of being known (Sophist 248e). This suggests that a form can have contrary properties. We would add with our revised reading that these properties are pros ta alla properties, as opposed to pros heauto 
properties, because ' $F$ is known' is a statement about the relationship between $F$ and souls. Rickless' evidence for claiming that forms must have contrary properties, then, seems indirectly to confirm our revision, at least in Sophist. In Philebus, Socrates and Protarchus base their discussion on showing of pleasure and knowledge 'how each of them is one and many' (Philebus 18e), because there are clearly different kinds of pleasure (sexual, culinary) and knowledge (theoretical, practical). This, again, is pros ta alla contrariness, as pleasure can be manifested in different ways, but its account does not require that it is either sexual or culinary: it is presumably more basic. Thus, again, Rickless' evidence makes more sense if we accept my emendation to the principle.

Thus, the final version of the blended Gill-Meinwald thesis is committed to five propositions:

(1) Parmenides' demonstration is meant to give Socrates the tools to respond to his objections in the first part of the dialogue.

(2) Parmenides' method develops a particular account of predication: $x$ can be $y$ insofar as $y$ is part of the account of $x$, or $x$ can have the property of $y$-ness.

(3) Parmenides' has shown that forms can self-predicate and that forms must partake in their contraries pros ta alla.

(4) Parmenides accepts that there must be forms.

(5) Parmenides accepts that the form of the One is an arche.

In the next chapter, we will see if this interpretation can stand up to a number of objections, and examine claim (5) in some specificity. I think that Meinwald's reading 
underdetermines this claim, but that it can be bolstered by a more thorough understanding of Parmenides' method. However, it seems that on examination, there is very little that is in tension with regard to the results of Meinwald's and Gill's views; the disagreement is primarily in grounding them. However, we can productively generate Gill's conclusions, with minor modifications, internal to Meinwald's thesis, and in doing so increase its explanatory power. Meinwald's reading seems better able to account for most of the elements that require explanation in Parmenides, and as a result should be taken as the core of a combined reading; however, Gill helps us better explain the choice of Parmenides as a character, certain lines at the start of the dialogue, and connections to the 'metaphysical' dialogues. That said, though, a closer examination of Parmenides' methodological remarks may help us to explain those parts of the text that our combined reading is incapable of taking on. 


\section{1: Outline of Chapter Three}

The interpretation advanced in Chapter Two leaves what I take to be two major holes in our reading of Parmenides: one obvious, and one less so. The first problem is that even a combination of Meinwald's and Gill's theses is incapable of explaining what it is about the conversation between Parmenides and Socrates that causes Cephalus to travel to Athens so many years later in order to hear a third-hand account of it. ${ }^{60}$ This seems to me to mark off the conversation as one of tremendous importance, which is further reinforced by the fact that Socrates' engages in it as a young man. None of the answers that we seem to be capable of proposing at this point adequately address this question. The second problem is that the combined account does not actually discuss Parmenides' instructions in their entirety. Parmenides tells Socrates to get training that consists in (a) reasoning in the manner of Zeno, (b) reasoning about objects that one 'might think to be forms' (135e), (c) hypothesizing both the existence and non-existence of the topic of the exercise, and (d) examining the consequences in the familiar systematic way that has warranted so much discussion over the last fifty pages. It is (c), I think, that remains under-discussed by our present account. Parmenides tells Socrates not simply to posit the existence and non-existence of a particular entity, but instead to hypothesize. ${ }^{61}$

I am going to argue in this chapter that these two holes in our reading are linked, due to a suggestion in Republic that what separates the true philosopher from everyone else is

\footnotetext{
${ }^{60}$ The current theory with which we are working would answer that Plato makes this the dialogue in which Socrates is the youngest, and as such makes it clearly important, because these problems with the forms are one of his most serious philosophical concerns. This is of course predicated on the claim that the forms are the centerpiece of Plato's philosophy. However, this is anything but clear; as Annas (2002) points out, the forms were not always considered central to Plato's philosophy, and this is a contingent feature of modern scholarship. I am taking no side on the developmentalist/unitarian debate, but I do claim that if we can find more of a reason to have this encounter be central, we have a better reading.

${ }^{61}$ Here I translate $u\left[\pi 0 T i \theta_{\varepsilon} \sigma \theta_{\alpha, 1}\right.$ which can also be rendered 'assume'.
} 
her ability to account for her hypotheses. In order to defend this claim, I will first show that the word 'hypothesize' is not here a throwaway with reference to Meno and Phaedo. Next, I will briefly try to show what it means to hypothesize for Plato. It must be emphasized here that it is impossible in the amount of space available to do justice to the varied controversies around the method of hypothesis; all that I can possibly accomplish is an overview. Nor do I suggest that I am going to revolutionize our account of the method of hypothesis in this chapter, though I do think that further research on Parmenides and hypothesis may well yield important results. Instead, I will be making the much more modest suggestion that it is a very technical kind of hypothesizing that Parmenides is recommending to Socrates, and its importance is understated by our current account. As a fortunate side effect of our discussion of hypothesis, I will try to ground Meinwald's claim that the one is an arche, a claim that I have left unexamined through the previous two chapters. In the closing section of this chapter, I will measure our final reading of Parmenides against the relevant parts of the heuristic and demonstrate its strength. It is only at this point that I will go on to sketch what I take to be the ethical implications for of dialogue, grounded in Plato's use of the method of hypothesis. We will, then, be exploring a few related claims:

(1) The method of hypothesis is central not only in Meno, Phaedo, and Republic, but further in Parmenides.

(2) Understanding Parmenides' instruction to Socrates to hypothesize helps to explain elements of the text that are difficult to give an account of without a methodological emphasis.

(3) Parmenides gives an argument for the one being an arche. 
(4) Parmenides' instructions to Socrates cause Parmenides to take on some ethical implications.

\section{2: The Method of Hypothesis in Phaedo, Meno, and Parmenides}

Meinwald, Gill, and to the best of my knowledge all other (English-speaking) readers of Parmenides, ${ }^{62}$ leave one key part of Parmenides' methodological remarks unexamined: his assertion that Socrates must hypothesize. Our typical understanding of what it is to 'hypothesize' as being equivalent to positing initially seems to explain what is happening in Parmenides. Parmenides in his deductions appears simply to assume that the one is, and derive the consequences of that assumption. As such, it seems that my claim that we have to pay close attention to Parmenides' use of the word 'hupotithesthai' may require some justification; we cannot simply assume that here the word has the same connotation in Parmenides as it does in Phaedo or Meno, two dialogues in which it refers to a special method. In order to make it clear that Plato uses 'hypothesize' here in a technical sense, I will draw out a number of parallels between instances of hypothesizing in Phaedo and Meno on the one hand and Parmenides on the other. If Parmenides' example bears a resemblance to those instances of hypothesis in Phaedo and Meno, then it seems that we can tentatively conclude that we are justified in thinking that Parmenides' use of hypothesis is related to the discussions of the method of hypothesis in the secondary literature around Phaedo and Meno.

Let us start with Phaedo. Near the end of the dialogue, Socrates seeks to show that the soul is immortal (100b). In order to do this, he must 'hypothesize ${ }^{63}$ the existence

\footnotetext{
${ }^{62}$ Kenneth Sayre, in Plato's Late Ontology, does actually have a paragraph about a contrast between hypothesis in Republic and Phaedo and Parmenides (Sayre 1983: 38). However, I do not think that he appreciates the interpretive potential of this part of the instructions, nor does he engage with Meno.

63 Grube renders this as 'assume', but the word is hupotithesthai.
} 
of a Beautiful, itself by itself, of a Good and a Great and all the rest' (ibid). That is to say, the starting point of Socrates' investigation into the existence of the immortal soul is the hypothesis that forms exist. The content and structure of that proof need not concern us here, though-what matters is that Socrates derives the existence of the soul by an examination of the consequences of his hypothesis, and it includes an extended rumination on the mechanics of participation. However, at the end of the deduction, he tells Simmias that their first hypothesis 'require[s] clearer examination' (107b). Further, Socrates outlines the manner in which this investigation should be conducted; he claims that in order to give an account of our initial hypothesis (that forms exist with certain properties), we would have to 'assume another hypothesis', and so on and so forth until we reach the 'best of the higher ones' (101e). That is to say, Socrates has suggested that we must investigate our opening hypothesis in order to be thorough; in this case, this means we must investigate two claims: (a) the existence of the forms, and (b) the properties of the forms, or how it is that the Beautiful is beautiful (100c).

There are two lessons to draw from Phaedo at this point, then. First, it seems that hypotheses are here used as we would typically understand them: they are assumptions made in order to ground a related but different point that is a consequence of the truth or falsity of the initial claim. Second, hypotheses themselves must be investigated in order to give a full account of the problem, and are generally investigated by positing a further, 'higher' hypothesis.

Let us turn now to Parmenides in comparison to Phaedo. It seems that the first point I have made in our preliminary investigation of the latter dialogue does not bear much of a relationship to Parmenides; though Socrates seems to be deriving the 
consequences of a hypothesis, he does not do so with any strict structure, except with the provision that he must keep separate a hypothesis and its consequences. What is striking about Parmenides' method, though, is the precise and systematic way in which he derives consequences; this is noticeably absent in the Phaedo account. On this point, then, it does not seem that Phaedo lends any support to my claim that Parmenides' hypothesizing should be understood as relevant to the literature on the formal method of hypothesis. ${ }^{64}$

The second point, though, is more interesting for our reading of Parmenides. Socrates emphasizes that in order to give a complete account of a subject, we must be able to account for our hypotheses. ${ }^{65}$ Recall here Socrates' response to Zeno, and Parmenides' response to Socrates. In order to engage with Zeno's paradox, Socrates has to have Zeno agree to a claim that is familiar from our quick detour through Phaedo: that 'there is a form, itself by itself, of likeness, and another form, opposite to this, which is what unlike is' (Parmenides 129a). Zeno does not challenge this claim; he assents just as Cebes does in Phaedo. What Parmenides later demands of Socrates, though, is an account of this assumption (or hypothesis), and this is what Socrates fails to give. To draw these threads together, when Parmenides is relating the outline of his exercise to Socrates, in which he tells him to hypothesize, he is doing so in the context of having shown Socrates that his initial hypothesis requires further examination. This, as we have seen, is a central feature of the discussion of the method of hypothesis in Phaedo. In the next section, I will draw this argument further and suggest that what Parmenides does in his exercises is

\footnotetext{
${ }^{64}$ That being said, the reading of Parmenides that we have been exploring here does match up with the first lesson of Phaedo to a certain extent. Parmenides' hypothesis, that the one is, seems to be of indirect relevance to answering problematic questions about the properties of the forms.

${ }^{65}$ Recall here the importance of 'having an account' for the analysis of knowledge in Theaetetus. Cf. Gettier (1963: 121, n.1). This seems to suggest that in order to have actual knowledge of a subject, as opposed to simply a belief, we must be able to account for the hypotheses that we use to generate our claims about that particular subject.
} 
provide the 'higher' hypothesis that Socrates references in Phaedo, but for now let it suffice to say that it seems that in Parmenides Socrates is made to examine his own hypotheses in order to give a full account of the forms, and that this is a central feature of what it is to hypothesize in Phaedo. It seems, then, that there is some preliminary reason to suggest that 'hupotithesthai' is here being used in a technical sense, due to its purpose in Parmenides matching up with part of the account in Phaedo.

However, it looks as if the structure of the method in Phaedo is not especially similar to that of Parmenides; in Meno, another dialogue that has an extensive rumination on what it is to hypothesize, the structure is much closer to Parmenides' method. In Meno, Meno is interested in investigating the question as to whether 'virtue is something teachable, or is a natural gift' (Meno $86 \mathrm{~d}$ ), or comes to be possessed in some other way. Socrates protests that this is a difficult question to answer without first having knowledge of what it is that virtue itself is. As such, he suggests that they proceed by hypothesis: that if virtue is knowledge, then it is teachable, and that if virtue is not knowledge, then it is not teachable (87d). Thus, the investigation proceeds by trying to decide on the truth of the claim 'virtue is knowledge', because a consequence of that claim is that virtue is teachable, on the assumption that knowledge is teachable. ${ }^{66}$ Socrates investigates the claim that virtue is knowledge, comes to the preliminary conclusion that it is, and as a result virtue ought to be teachable. He finds, though, that a consequence of this view is that virtuous men ought to have taught their sons to be virtuous if it was something that could be taught; if they are virtuous, then they must by definition desire the good for their

\footnotetext{
${ }^{66}$ This latter assumption, of course, leads to Meno's Paradox-that it is unclear how we can learn something we do not already know. However, the truth of the assumption is irrelevant to the structural considerations we are investigating here.
} 
sons, and being virtuous is the good, so they must want to teach their sons (93c). This causes Socrates to take his own advice from Phaedo: in order to come to a full account of our subject, we must examine our hypotheses separate from their consequences. As a result, he proceeds to investigate the truth of his initial claim: that everything that is knowledge is teachable $(87 \mathrm{c})$.

This instance of the method of hypothesis seems to bear some stronger similarities to Parmenides. Parmenides presents Socrates with questions about the properties of an entity for which he does not yet have an account, just as Meno presents Socrates with questions about the properties of virtue without knowledge of what virtue itself is. Socrates' solution in the latter case is to propose a separate, related topic of investigation that through its answering would provide an answer to the initial problem. It may be the case, then, that Parmenides presents his hypothesis - that it is one-as an investigation that will in principle help us to find the answer to his problems. This, indeed, is one of the foundational points of both of the major readings of Parmenides that we have discussed here: the link between the two major parts of the dialogue is that Parmenides provides Socrates with either the tools or the conceptual solution to escape his objections. This seems structurally to match up with the use of hypothesis in Meno. As such, I think we are justified in concluding that what is going on in Parmenides' methodological remarks and his example is that he is urging Socrates to partake in a formal, systematic method of hypothesis. As such, we will investigate in the next section what it means to hypothesize, and what implications that has for our reading of Parmenides.

\section{3: Hypothesis, Formalized}


What Plato means when he uses 'hypothesize' has been a subject of much debate, especially regarding its use in Meno. It has been argued that the method of hypothesis is for Plato a way to generate positive knowledge, as opposed to the removal of false belief (Benson 2003: 95). That is to say, after we reach aporia, like Socrates does in the first part of Parmenides, the use of elenchus is exhausted; if there are no false beliefs left of which to cure Socrates, then there seems to be no way forward in the standard manner of elenchus. As Benson puts it, ' $[\mathrm{t}] \mathrm{he}$ method of hypothesis provides one who is ignorant of what one is searching for with a place to start' (Benson 2003: 99). Since this seems adequately to describe the discussion at the transitional section between the two parts of Parmenides, and it is precisely at this section that Parmenides introduces the notion of hypothesizing, understanding both how hypothesis works and what its purpose is may be illuminating. Further, without elaborating on what it means to hypothesize, it seems difficult to make a principled distinction between the method articulated by Parmenides in the Meinwald-Gill account with which we have been working and a more fleshed out version of Socratic elenchus; it is not obvious how, when confronted simply with the structure of the deductions, Parmenides plans to generate positive knowledge. That is to say, Socrates in every dialogue deduces the consequences of the positions put forward by his interlocutors. This is the core of the elenchus: he draws out the beliefs that his interlocutor is committed to by virtue of their initial position until they come into conflict with another belief that interlocutor holds. If Parmenides is simply proposing a method that is a systematization of Socrates' standard elenctic method, which itself has some difficulty generating positive knowledge, then it is not clear how it will provide justification for Socrates' true belief that there are forms. 
Finally, as Kahn points out, 'it is the use made of hypothesis that distinguishes dialectic from mathematics' (Kahn 1996: 309). More precisely, mathematicians are happy to derive the consequences of a particular hypothesis, but unwilling or unable to give an account of the hypothesis itself; the latter is the job of the dialectician (Kahn 1996: 318$).{ }^{67}$ As a result, the fundamental task that distinguishes the dialectician and philosopher from the 'mere' mathematician is the ability to 'give an account' of her own hypothesis. The method of hypothesis, then, is of central importance. Thus, a quick digression to Meno can be read alongside the Meinwald-Gill interpretation of Parmenides' method to see if we can improve the latter. ${ }^{68}$

Socrates introduces the method of hypothesis in Meno with an analogy to how geometers solve problems when they are not sure where to start. The passage has a great deal of important data for our study of how hypothesis might work in Parmenides, so I will quote it in full, and then pull sections out to discuss one at a time.

If [geometers] are asked whether a specific area can be inscribed in the form of a triangle within a given circle, one of them might say: 'I do not yet know whether that area has that property, but I think I have, as it were, a hypothesis that is of use for the problem, namely this: If that area is such that when one has applied it as a rectangle to the given straight line in the circle it is deficient by a figure similar to the very figure which is applied, then I think one alternative results, whereas another results if it is impossible for this to happen. So, by using this hypothesis, I am willing to tell you what results with regard to inscribing it in the circle that is, whether it is impossible or not.' So let us speak about virtue also, since we do not know either what it is or what qualities it possesses, and let us investigate whether it is teachable or not by means of a hypothesis... (86e-87b)

\footnotetext{
${ }^{67}$ Cf. Republic 510c-e.

${ }^{68}$ Here again there is a minor contact point with Aristotle that suggests that hypothesis bears some importance. In Posterior Analytics, Aristotle defines a supposition or hypothesis as an assertion or denial of the existence of an entity in a proposition, which he further defines as one half of a contradiction (Posterior Analytics 72a21). A hypothesis is concerned explicitly with the being or non-being of an entity; Aristotle calls any assertion about the properties of an entity a definition, not a hypothesis. As he makes the distinction, 'what a unit [definition] is and that a unit is [hypothesis] are not the same' (72a24).
} 
First, note the way the geometer's method works. When confronted with a question to which she does not have an answer, she asks a different question which can indirectly satisfy the first, which we noted in the previous section. As Benson puts it, she tries 'to reduce the original question...to another question' (Benson 2003: 104). This second question has a bearing on the first such that if it is answered in the affirmative, one alternative results, and if it is answered in the negative, the other does. That is to say, if the question at issue is whether $x$ is true or false, then the geometer proposes that we investigate $y$, as $y$ is true if and only if $x$ is true, and vice versa. Thus, the geometer suggests that we investigate $x$, about which we have no knowledge, through $y$, because the truth of $y$ guarantees the truth of $x$ and the falsity of $y$ guarantees the falsity of $x$. The purpose of a method of hypothesis, then, is dual: first, to generate positive knowledge, and second, to investigate indirectly subjects about which we have no direct knowledge. This is illustrated in the passages that follow Socrates' analogy to the geometer, in his investigation of virtue. It seems that Socrates (a) generates a hypothesis to investigate a claim about which he lacks knowledge, (b) tests both that hypothesis and its negation, and (c) does that testing by the examination of consequences of hypotheses. ${ }^{69}$ This looks very much like a version of the method of Parmenides without a fleshed-out notion of the 'in relation to' qualifiers.

\footnotetext{
${ }^{69}$ There are two different kinds of 'testing', both of which are at work in Parmenides. The first kind is testing the consequences of a hypothesis by examining its logical implications; this is what makes up the vast majority of the second part of the dialogue. However, it is also the case that we make use of empirical data in order to test Parmenides' hypothesis. Specifically, he finds that a logical consequence of the one not being is that nothing is; our reading holds that we are to conclude from the empirical fact that it is not the case that nothing is that we are to hold that the one in some sense or another exists.
} 
What conclusions then can we draw about Parmenides' method from the geometer's strategy and Socrates' application of it? First, if Parmenides' method of hypothesis is understood to be similar to the geometer's, which I have argued it should, then Parmenides is demonstrating a way to investigate claims about topics about which we lack knowledge of the properties of the subject under discussion. ${ }^{70}$ This describes Socrates' position at the transitional passage of Parmenides precisely; Parmenides has affirmed that Socrates has a true belief in the existence of the forms, but he has no account of them. Thus, what we should expect Parmenides to be demonstrating is an indirect method of coming to knowledge of the forms or form-like objects, given that we take the problem at the transitional passage of Parmenides to be that Socrates does not know the properties of forms. ${ }^{71} \mathrm{~A}$ focus on the notion of hypothesis seems to predict that there will be two points to Parmenides' demonstration: first, that Parmenides shows precisely how to derive consequences properly, and second that Parmenides provides information indirectly relevant to giving an account of the forms.

It seems that the Meinwald-Gill reading of Parmenides matches both of these implications. First, the method, which ends in aporia in Meno because Socrates does not yet derive the exhaustive consequences, is made precise by the systematization of the

\footnotetext{
${ }^{70} \mathrm{~A}$ major difference has been pointed out to me between the two. It seems that there is a question to answer in the example of the method of hypothesis in Meno-the geometer is trying to say 'whether a specific area can be inscribed in the form of a triangle within a given circle' (87a), and Socrates is trying to answer whether virtue is teachable. As such, it is unclear how we can say that the same sort of investigation is at work in Parmenides if there is no obvious topic of investigation; it certainly looks as if Parmenides is just deriving the consequences of 'it is one', at most as a demonstration of a method that may bear some relevance to Socrates' aporia. However, our current reading rides on the viability of the claim that the second part of the Parmenides is indirectly relevant to the first part; even if it is gymnastic, it spurs us, and Socrates, to make the distinction necessary in order to solve Parmenides' problems in the first part of the dialogue. I would contend, then, that the question under examination is something like 'what are the properties of the forms?'.

${ }^{11}$ The alternative, of course, is that Parmenides has arbitrarily chosen his subject and is discussing 'if it is one' solely as an example. While I do not deny this as a possibility, see Chapter Two for a discussion that suggests that we can assign further importance to this particular choice.
} 
consequences that have to be drawn and the distinction between the two types of predication; second, one of the surprising claims that Meinwald and Gill have in common is that Parmenides indirectly provides Socrates with the tools necessary to come to an account of the forms.

So far, we have focused on what Kahn calls the 'downward path' of the hypothesis. That is, we have only talked about the importance of the derived consequences of a particular proposition that we have granted for the sake of argument. More interesting for Parmenides is the 'upward path' that helps to distinguish the mathematician from the philosopher in Republic. Socrates in Phaedo claims that there are two separate tasks for the good philosopher: giving the consequences of his hypothesis, and giving an account of that hypothesis itself. Usually, this account tethers the hypothesis under consideration to a 'higher', more fundamental hypothesis. In Phaedo, as noted above, Socrates bases his claim for the immortality of the soul-which is still strictly speaking a hypothesis by the end of the dialogue, given that he calls it a noble risk-on the assumption that there exist forms. The hypothesis that there exist forms, then, is in this case a higher one. However, the philosopher assesses his higher claims, too. Kahn argues that given that the first part of Parmenides seems explicitly to be concerned with testing the forms, we can understand the dialogue to be concerned with this task: giving an account of Phaedo's higher hypothesis (Kahn 1996: 319). There is good reason to think that this is the case. At the transitional section of Parmenides, Socrates is brought to aporia about the forms. However, Parmenides does not stop here, but instead says that forms must exist, or dialegesthai [dialectic] is impossible (135c). Thus, Socrates has a true belief about the existence of the forms, but cannot give their 
logos or an account of them. Parmenides seems to be giving him the tools necessary for that account. In doing so, he make an argumentative move parallel to that of Phaedo. In Phaedo, Socrates predicates the existence of an immortal soul on the forms, and thus moves it 'upward' to a higher hypothesis. However, this higher hypothesis is not clearly a self-justifying one, at least in the context of Phaedo; as I noted above, Socrates still refers to belief in the immortality of the soul as a 'noble risk' (114d). ${ }^{72}$ In Parmenides, it seems that Parmenides moves the account for the existence of the forms up to the existence of the one. ${ }^{73}$ However, this has an advantage over his move in Phaedo. Forms cannot justify their own existence, or give their own account; the form of the one that is the subject of Parmenides' deductions, though, seems able to prove its own existence, and give an account of itself. We will explore this in the next section.

\section{4: The One as Arche or Unhypothetical Starting Point}

This leads us to a consideration of Meinwald's last claim. Recall that at the transitional passage of Parmenides, Parmenides makes an implicit argument for the existence of the forms based on a conditional: if there are no forms, then discussion (or dialectic) is impossible. No matter how we construe dialegesthai here, the consequent is clearly denied by the text surrounding the claim, as there has been and will be a substantial amount of dialogue in Parmenides, and dialectic has been employed by both Socrates and Parmenides. The key thing to note for the purposes of this argument is that Parmenides' point is made by appealing to something clear from the context of the conditional; if we

\footnotetext{
${ }^{72}$ Someone might object that 'the Beautiful is beautiful' is necessarily true by reason of tautology (100c). If that's the case, then Socrates' conclusion is non-hypothetical; his hypothesis self-justifies. However, as we have seen in chapter two, the predication of a property on a form is not as simple as the proposition would lead us to think; we have to give an account of how it is that that predication takes place.

${ }^{73}$ Note that 'account' here is not simply 'reason to think that $x$ is true/exists'. A logos of $x$ includes some principled way of talking about its properties, definition, and further.
} 
say that speech is impossible, we are pragmatically contradicting ourselves by the act of locution, and if Parmenides is claiming dialectic is impossible without the forms, we have good reason to think that dialectic is possible, given that Parmenides seems to be utilizing it. The context of the presentation of the conditional, then, seems to imply a response to it. In parallel, consider the conditional 'if one is not, then nothing is' (166c)-one of the last lines of the dialogue. Parmenides does not evaluate the conditional at the end of the dialogue, much as he does not evaluate the claim that if there are no forms, dialegesthai is impossible. However, it is clear on reflection from context that 'nothing is' is not the case; it is impossible to deny the proposition, especially given that Parmenides seems to be speaking, and that implies that Parmenides in some sense is. ${ }^{74}$ Thus, we can here too deny the consequent; it is not the case that nothing is, thus it is not the case that the one is not. As a result, we can infer from the fact that the final deduction is asserted that, if the rest of the reasoning by which Parmenides got there is valid, the one is. Given that it is impossible not to deny the claim 'nothing is', the existence of the one represents an unhypothetical starting point; Parmenides has reasoned backwards to the proposition that can act as a first principle in the rest of our deductions, because it is necessarily true. As a result, Meinwald seems justified in claiming that the one is, in Parmenides' argument, an arche simply from the results of the eighth deduction.

However, we can strengthen the argument for this claim if we grant that Parmenides is employing a formal method of hypothesis. If the most significant part of the method of hypothesis is that it engages in trying to give an account of its own assumptions, and the forms represent a basic assumption in Phaedo, then it seems that an

\footnotetext{
${ }^{74}$ We can go down many levels of skepticism from here, but it seems to me that the claim 'nothing is' cannot reasonably be asserted, because there has to be something to assert it.
} 
act of reasoning that tries to ground the existence of the forms is necessarily one of the higher, if not the highest, hypothesis. Given that the highest hypothesis would ideally be the unhypothetical starting point about which Socrates talks in Republic during the analogy of the divided line, we have some principled reason to think, independent of the second part of the dialogue, that we will be discussing an entity that has the potential to be an arche simply from Parmenides' methodological remarks. Thus, the methodology as well as the argument leads us to support Meinwald's claim that the one is an arche; we can, in our interpretation, take it to be one of the upshots of the second part of the dialogue. $^{75}$

More interesting for our analysis, though, is that if Parmenides' method is capable of giving an account for hypotheses, then this provides us with some reason that Cephalus comes to Athens to hear a third-hand account of the conversation, and thus solves one of the major remaining problems with our reading. Recall that what separates the mathematician from the philosopher is that the philosopher can give an account of his hypotheses, while the mathematician is only capable of deriving the consequences of his hypotheses that he assumes to be axiomatically true (Republic 510c-e). If Parmenides is concerned with helping Socrates to ground the forms, and also manages to ground his own hypothesis, then he has taught Socrates quite simply how to be a philosopher. If the good life is the philosophical life, then it is clear that Parmenides' lesson has some central importance for Cephalus; in order to live the good life, he must master the techniques that

\footnotetext{
${ }^{75}$ I do not want to assert baldly that the highest hypothesis is the subject of the deductions in Parmenides. There is a great deal of very thorough argumentation about the identity of the highest hypothesis. I simply want to point to the possibility that this is the case, pending further investigation.
} 
define the philosopher. ${ }^{76}$ This method, given its importance, would be enough to both have someone passionate about philosophy travel to hear a memorized version of the conversation in which it is expounded, and have it be the dialogue in which Socrates in the youngest. This better explains the available data about importance than any of the previous claims in the Meinwald-Gill theory; it seems unlikely that Cephalus would visit from Clazomenae to learn about self-predication, the participation of forms in their contraries, or the intricacies of relationality-vital as those may be for rescuing the forms-unless there is something central to the practice of philosophy in Parmenides' conversation with Socrates. ${ }^{77}$

Placing increased weight on the notion of hypothesis as a method that is entirely distinct from typical Socratic elenchus, aside from helping solve our problem with Cephalus' journey, allows us better to explain the employment of the dialogue form through Parmenides. It has yet further benefit in helping us to distinguish between Socratic elenchus and Parmenides' method as a distinction of type, as opposed to token. The opening section of Parmenides is in most ways a typical dialogue; there is a substantial amount of conversational back-and-forth, and two interlocutors are disabused of their beliefs by the application of elenchus. On the other hand, the second part of the

\footnotetext{
${ }^{76}$ There are further reasons to think this from Republic. Near the end of the dialogue, Socrates evokes the Myth of Er. In it, he discusses a person who 'had participated in virtue through habit and without philosophy'; he is just, but not self-reflectively so (Republic 619c). This matches the description of the Cephalus of Republic. This Cephalus, in book one, has described old age as a blessing as it caused his 'appetites to relax' (329c). He is portrayed as moderate, kind, and just, but has no interest in philosophy; he quickly 'hand[s] over the argument' with Socrates to Polemarchus (331d). The Cephalus of Parmenides, then, may well seek remedy his namesake's flaw-he is virtuous and philosophical, and thus lives the truly good life.

${ }^{7}$ We find a similar passage in the Gorgias. Socrates claims that someone is practicing a techne [an art or craft in the modern 'liberal art' sense of the term] only if an account can be given of the elements of that practice (Gorgias 465a). If philosophers deal in those topics that are accessible only to the mind, then the proper philosopher will be able to give an account of those entities; otherwise, he is merely practicing a 'knack' as opposed to an art.
} 
dialogue is unique in Plato's corpus. As Meinwald puts it, 'a single introductory phanai... ${ }^{78}$ introduces almost thirty Stephanus pages of uninterrupted argument (Meinwald 2005: 17); though it is ostensibly a dialogue, Aristoteles does not have much of a role to play in the conversation. Parmenides very clearly does all of the conceptual 'heavy lifting' here. Further, there is no other interjection of 'he said' in the second part, simply a question and answer exchange. In contrast, for example, to Phaedo, where the temporally removed narrators occasionally move back to the original frame and comment on what is happening in the story, we never shift back from Parmenides' deductions to Cephalus. This lack of narrative interference in the second part does, as Meinwald claims, help involve 'us' in the dialogue and thus enhances the gymnastic effect (Meinwald 2005: 19), but if we accept my interjection about the formal methodological features of hypothesis, we can say substantially more about this stylistic distinction between the two parts of the dialogue. By emphasizing 'hypothesizing' as a method distinct from that that is used in the first part of the dialogue, we can suggest that the stylistic and structural differences between the parts of Parmenides serve to make a methodological distinction stark with the help of a compositional distinction. This can be said in addition to the claims that (a) the second section is designed to be exhausting and give the reader a proper conception of precisely how difficult the exercise Parmenides has Socrates carry out is and (b) that the composition of the second part more closely involves us in the dialogue; these options are not limited by the methodological focus.

Further, it seems that without some modification, the Meinwald-Gill thesis has difficulty accounting for the use of the dialogue form. Meinwald notes that 'we should

\footnotetext{
${ }^{78}$ Translated in this context as 'he said'.
} 
not assume in advance that the generic significance of dialogue form will exhaust all there is to say about more specific types and about all particular cases' (Meinwald 2005: 9), but, while giving an account of the stylistically distinct second part of the dialogue, it does not give a similarly thorough account of the more traditional first part. I have argued that we can add to her remarks consistently by claiming that the standard elenchus in the first part of Parmenides represents the standard Socratic method, whereas the cessation of dialogue, construed in any meaningful way, helps make stark the contrast we have been discussing; even though in both Meno and Phaedo we see hypothesis happening in the context of a dialogue, if these methodological contrasts are as significant as I have argued that they are, we can see why Plato would choose to end all dialogue after the transitional passage in the Parmenides, and make clear that very different kinds of reasoning are used in the first and the second parts. Indeed, this is made more clear by paying attention to the types of questions asked in the late parts of Parmenides; instead of asking, for example, what properties the forms have, Parmenides asks Aristoteles simple 'yes' or 'no' questions, asking him to confirm or deny Parmenides' own position, not to propose an answer to any of the conceptual problems of his own. Other than Meinwald's claim that the unusual structure of the second part of the dialogue helps emphasize its gymnastic elements, which is plausible, the Meinwald-Gill reading cannot account for the dialogue form. ${ }^{79}$ By making one of the focal points of the dialogue Parmenides' methodology, though, we can better emphasize the importance of each of the parts, and give a

\footnotetext{
${ }^{79}$ The statement seems to be based on the kind of claim Epictetus makes about philosophers and athletes. Just as an athlete does not want an opponent who is a pushover, philosophers are not well served by easy problems. The more challenging the exercise, the more benefit the philosopher is meant to get out of it.
} 
principled reason that Plato would make use of standard elenchus in the first part of Parmenides.

Next, Meinwald's account of the presence of Glaucon and Adeimantus is not thoroughly fleshed out. Recall that she makes a compelling argument for the use of Antiphon and Cephalus; they both forecast one of the primary conceptual points of the dialogue in their examination of homonymy. In Meinwald's reading, Glaucon and Adeimantus simply help contextualize Cephalus and remind us of Republic, helping to convince us that the choice is no coincidence. This is possible, but the part of Republic in which Cephalus is involved does not feature Glaucon and Adeimantus prominently; it is only after he leaves, and Thrasymachus gives up, that they take a major role in the dialogue. A character that would better evoke the Cephalus of Republic, then, would be Thrasymachus or Polemarchus. Glaucon and Adeimantus seem as if they have further significance in a reading that takes as central Parmenides' methodological remarks. It is in conversation with Glaucon and Adeimantus that Socrates discusses the principle of investigating from hypothesis in Republic. Specifically, he claims that the soul, 'proceeding from a hypothesis...[and] using forms themselves', makes its way to a 'first principle [arche]' (Republic 510b). That is to say, by means of hypothesis, we can discover an unhypothetical starting point for our reasoning. I argue, with Meinwald, that the subject of the deductions of the second part function as an arche, though given the Aristotelian technical connotations of the word, I prefer 'unhypothetical starting point'. If I am right, the second part of Parmenides represents the culmination of the discussion of the line in Republic. I agree with Meinwald, then, that the subject of Parmenides' deduction is a plausible candidate for an arche; I would add, though, that this claim has 
Iain Laidley

The Problem of Parmenides

Chapter 3

implications for the practice of philosophy, not just metaphysical ones, and do not think that she gives significant argument for it. Again, by shifting the focus to the significance of Parmenides' methodological remarks, we can make the choice of Adeimantus and Glaucon, as characters, more significant.

It seems, then, that there are strong interpretive reasons to add my methodological emphasis to the combined Meinwald-Gill account. This brings us to the following list of claims:

(1) Parmenides' demonstration is meant to give Socrates the tools to respond to his objections in the first part of the dialogue.

(2) Parmenides' method develops a particular account of predication: $x$ can be $y$ insofar as $y$ is part of the account of $x$, or $x$ can display the property of $y$-ness.

(3) Parmenides' has shown that forms can self-predicate and that forms must partake in their contraries pros ta alla.

(4) Parmenides accepts that there must be forms.

(5) Parmenides accepts that the form of the One is an arche.

(6) Parmenides is developing and applying the method of hypothesis, central to the work of the philosopher as distinct from a mathematician, Socrates uses in Phaedo and Meno.

This brings to the forefront a dilemma for any reading that posits hypothesis in Parmenides as a development of the method of Phaedo and Meno. If we lend this interpretive weight to Parmenides' instruction to Socrates that he must hypothesize, then it seems we are left with the question of why Socrates would, as a young man, have 
The Problem of Parmenides

learned a thorough and systematic way for deriving the exhaustive consequences of a particular set of hypotheses, and as an old man decided not to apply it. It is clear that in Phaedo and Meno, Socrates does not derive consequences according to the pros heauto/pros ta alla schema; though he may examine a hypothesis and its opposite, he does not make a clean distinction between those properties which are displayed in relation to some other entity and those properties that are part of the subject's account. This is a problem, then, of narrative coherence. Socrates routinely suggests that Parmenides was highly influential on his own thinking, ${ }^{80}$ but the primary innovation that Meinwald argues is the lesson of Parmenides is absent in much of the rest of his work when it would be relevant. That is to say, because Meinwald suggests that Parmenides represents a better way of generating positive knowledge for Plato than he had prior, those dialogues that may have been composed prior to Parmenides are, when they employ hypothesis, not coherent with the narrative line of Socrates' life. As a young man, Socrates has a more developed way to hypothesize than he does on the day of his death.

We should not overestimate the severity and importance of the conflict here, though. It does not follow from the fact that Socrates as a young man is taught a fully worked-out system of hypothesizing that that is the system he communicates to Phaedo, Glaucon, or Adeimantus. Indeed, Parmenides makes clear in the transitional passage of the dialogue that the method is only accessible to Socrates because he has an exceptionally keen philosophical mind; he claims that '[o]nly a very gifted man can come to know that for each thing there is some kind, a being itself by itself; but only a prodigy more remarkable still will discover that and be able to teach someone else who has sifted

\footnotetext{
${ }^{80}$ Cf. Sophist $217 \mathrm{c}$ for an explicit reference to Socrates' conversation with Parmenides, for example. Indeed, in this passage he explicitly cites Parmenides' influence on his own style of reasoning.
} 
all those difficulties thoroughly and critically for himself' (135b). Though Glaucon, Phaedo, and Adeimantus are proven to be competent interlocutors, it is uncontroversial to claim that they are hardly prodigies. Further, we could reasonably claim the dramatic contexts in which Socrates discusses hypothesis in Phaedo, Meno, and Republic are not as centrally concerned with the details of the method; the context in Parmenides is more appropriate to this sort of exposition. As such, that Socrates communicates to them just the conclusion of this method, not the details of its execution, should ultimately be unsurprising to us.

\section{5: Reflecting on the Strength of the Revised Meinwald-Gill Theory}

On reflection, it seems that by combining the Meinwald and Gill readings of Parmenides, and adding to them what I have called here a methodological focus, we are better able to explain some of the most puzzling parts of Parmenides. Specifically, we have seen that we are better able to address a major hole in the combined account: the reason that Cephalus makes a journey to Athens to hear the conversation between Parmenides and Socrates. Further, this addition to our account lets us make use of all of Parmenides' methodological remarks, gives us better reasons for the presence of the minor characters, and helps us to explain the use of the dialogue form in the first part of Parmenides.

This reading has at least two further virtues beyond direct textual interpretive power, though. First, it does not commit to any claim about the 'primary point' of Parmenides; instead, it claims that there are six significant philosophical developments in the dialogue. This prevents the reading from getting bogged down in an argument about which development is the most important, as it simply asserts that they are all present in Parmenides and takes no position on their relative importance to each other. Similarly, 
my proposed reading does not try to fit into Proclus' logical/metaphysical categories, as a result of not trying to pin down the central message of the dialogue.

Finally, recall my three goals in this thesis. I want to show that (a) there are no real contradictions of significance between Gill and Meinwald, and their theories can be combined productively, (b) that the theory produced by (a) still fails to account for a certain amount of textual data that we can explain by paying attention to the method of hypothesis, and (c) that the theory produced by (a) and (b) would make us better able to integrate Parmenides into Plato scholarship as a whole. One of the major advantages of being a pluralist about the key innovations in Parmenides is that it allows for easier engagement with the broader paradigms of Platonic scholarship. If we hold, as M. L. Gill does, that the only philosophical developments in Parmenides are about the behaviour of the forms, then the dialogue is only useful for metaphysicians. However, as I hope I have demonstrated, it does not seem that the sole philosophically significant innovations in Parmenides are about the nature of the forms; there are, without a doubt, methodological and logical innovations as well. This broadens the field in which Parmenides can be used in arguments about Plato. It seems that if the best interpretation is that which plausibly and powerfully explains the elements of Parmenides, then the one that I have proposed here is at least the strongest available candidate.

\section{6: Concluding Remarks: the Young Socrates and an Art [techne] of Life}

If what I have written so far is correct, then we have good reason to think that there is more to talk about in Parmenides than metaphysics. In my closing remarks, I would like to sketch one of the primary thrusts of my reading that, with development, could well be 
relevant to a number of paradigms of the analysis of Platonic ethics. ${ }^{81}$ Before beginning, though, it must be emphasized that this is speculative work; I am here drawing out what I take to be the shape of future work on the Parmenides. I will argue for my claims, but we will not find the detailed textual analyses necessary to bring them to fruition here. As we noted in our discussion of the reason for Cephalus' journey to Athens, it seems that one of the central conditions for being a philosopher is the ability properly to use the method of hypothesis that, if I am right, is outlined in Parmenides. That is to say, to be practicing the craft of philosophy properly, we must aim at being able to give an account of our hypotheses; in order to give an account of our hypotheses, we need to understand Parmenides' method. To live the philosopher's life, then, we must make use of Parmenides' lesson to Socrates. As I noted above, then, if the good life is the philosophical one-or, as in Philebus, is close to the life of reason (67a)-then Parmenides gives us one of the most detailed analyses of what it is to live the good life, or at least what is necessary for the exercise of that life.

There are further elements of the text that suggest this possibility. First, not only is the philosophical life conceivably the good one, but it is hard to deny that in some sense Socrates is presented as a model of both what it is to do philosophy, and to live life

\footnotetext{
${ }^{81}$ There are at least two more ways that our account of Parmenides could be ethically important. First, anyone, like Irwin (1995), who thinks that Platonic ethics is tied up with his epistemology, and an important part of being good is knowing what the Good is, must also think that the method of hypothesis is vitally important. As a result, Parmenides' novel use of the method may lead us to reconsider, on further study, how it is that we are to come to know the Good. Second, a therapeutic paradigm like Nussbaum's (1994) holds that a philosophical method, if that philosophy is therapeutic, is meant to reduce human suffering. Here too, then, methodology is central, especially given that while elenchus is meant to purge beliefs, hypothesis seems to be designed to create and justify new ones. However, assessing the implications of our reading of Parmenides for these two paradigms would be a separate project altogether.
} 
well. ${ }^{82}$ We should be careful to note that Socrates is the youngest we ever see him in the Parmenides if the life of Socrates is ethically significant. Socrates' youth is made clear to us, and indeed emphasized, in the opening of the dialogue. Not only are we told that 'Socrates was...quite young' (127c) when the exchange with Zeno and Parmenides took place, but further Parmenides makes a point of emphasizing his age. Parmenides tells Socrates to get training while he is 'still young' (135d), and contrasts his own advanced age with Socrates' youth. Finally, Socrates behaves like a young man in his exchange with Zeno. Instead of being subtle in his insults, as he is later in life, Socrates is abrupt and straightforward with Zeno. He mocks Zeno, suggesting that in his book he has tried 'to fool [readers] into thinking he is saying something different' than Parmenides (128a), and suggests he does this not for any independent philosophical reasons, but instead because of fealty to his teacher. He further dismisses Zeno's argument as unimpressive; he would be 'astonished' (129b) to find that forms partake in their opposites, but the fact that particulars do is apparently uninteresting to him. The tone of his discourse with Zeno is signaled by Pythodorus' observation that throughout Socrates' exchange, Pythodorus 'kept from moment to moment expecting Parmenides and Zeno to get annoyed' (130a); it is implied that it is as a result of patience that they do not get angry with Socrates. As such, it is no small detail of the dialogue that Socrates is in his interaction with Zeno and Parmenides quite young, and it is a drawback of our reading that greater weight is not put

\footnotetext{
${ }^{82}$ It should hardly require much argument to make this claim minimally plausible. A number of dialogues, like Protagoras, open with a character asking Socrates for advice on how he ought to live his life. Others, like Symposium or Republic, have other characters actively and persistently elicit his opinions and company. Unsympathetic characters like Euthyphro seem designed to demonstrate the goodness of Socrates relative to his peers. Finally, at the end of Phaedo, we are told that Socrates 'was of all of those we have known the best, and also the wisest and the most upright' (118a). There is no ambiguity about Socrates' goodness, here. Later thinkers have similar reactions. Nehamas (1998) dedicates three chapters to Socrates' 'art of living', and the essays on later thinkers like Nietzsche and Montaigne too seem to be focused on grappling with what it is to live like Socrates.
} 
on this point. I suspect an ethical reading of Parmenides would take Socrates' age to be central. If Socrates is the symbol of what it means to live a good life, and there is at least some obvious difference between the young Socrates of the Parmenides and the old Socrates as portrayed in other dialogues, then there is potential that what the young Socrates learns immediately after he engages with Zeno is part of what makes his life good. This is a central topic for further investigation in Parmenides, alongside the more metaphysical considerations.

In the preceding, I have tried to make a very small contribution to the solution to a slightly larger problem. My goal in the first chapter was to show that the interpretation of the Parmenides can be broken down into a set of questions, and that we can better read the dialogue by trying to answer them. This prevents us from overemphasizing our pet issue-as I would like to do with Socrates' age!—or from overlooking a clearly important part of the text. In the second chapter, I applied this heuristic to a representative of each of the putatively distinct major interpretive traditions: the accounts of Constance Meinwald and M. L. Gill. We found, on examination, that the differences between their readings were slight, and that with some argument the two were compatible. By the end of the second chapter, our heuristic had made it clear that there were some serious flaws in the combined reading, even granting that they can seamlessly be combined in the first place. We addressed those flaws in the third chapter, and developed the start of an account for the 'hypothetical' reading of the Parmenides. In it, we emphasized Parmenides' remark that Socrates should hypothesize if he wants to reach truth, and drew on the secondary literature around the method of hypothesis to show that Parmenides, typically regarded as a metaphysical dialogue, had some ethical content. If 
The Problem of Parmenides

this project has been successful, then I hope to have convinced at least one reader that the Parmenides has been under-interpreted, and that with careful attention to detail, we can eventually use it as a source for the revision of our views on Plato's ethics. 


\section{Works Cited}

Allen, R. E. (1997). Plato: Parmenides. New Haven, Yale University Press.

Ambuel, David (2005). 'On What is Not, Eleatic Paradox in the Parmenides and the Sophist', Plato's Parmenides: Proceedings of the Fourth Symposium Platonicum Pragense, pp. 200-215.

Annas, Julia (ed.) (2002). New Perspectives on Plato, Modern and Ancient. Cambridge, Harvard University Press.

Barnes, Jonathan (ed.) (1984). The Complete Works of Aristotle. Princeton, Princeton Univeristy Press.

Benson, Hugh (2003). 'The Method of Hypothesis in the Meno', Proceedings of the Boston Area Colloquium in Ancient Philosophy 18, pp. 95-126.

Burnet, John (1901). Platonis Opera. Oxford, Oxford University Press.

Cooper, John M. (ed.) (1997). Plato: Complete Works. Indianapolis, Hackett.

Cornford, F. M. (1939). Plato and Parmenides. New York, Routledge.

Dillon, J. M. (2005). 'Speusippus and the Ontological Interpretation of the Parmenides', Plato's Parmenides: Proceedings of the Fourth Symposium Platonicum Pragense, pp. 296-312.

Forrester, James (1975). 'Arguments an Able Man Could Refute', Phronesis 19 (3), pp. 233-237.

Gettier, Edmund (1963). 'Is Justified True Belief Knowledge?', Analysis 23(6), pp. 121-123.

Gill, Mary Louise (1996). Plato: Parmenides. Indianapolis, Hackett.

- (forthcoming). PHILOSOPHOS: Plato's Missing Dialogue. Oxford, Oxford University Press.

Irwin, Terence (1995). Plato's Ethics. Oxford, Oxford University Press.

Kahn, Charles (1996). Plato and the Socratic Dialogue. Cambridge, Cambridge University Press.

Meinwald, Constance (1991). Plato's Parmenides. Oxford, Oxford University Press.

- (2005). 'Literary Elements and Dialogue Form in Plato's Parmenides', Plato's Parmenides:

Proceedings of the Fourth Symposium Platonicum Pragense, pp. 9-20.

- (forthcoming). 'How Does Plato's Exercise Work?', Proceedings of the First International Conference on Plato's Parmenides. 
Miller, Mitchell (1985). Plato's Parmenides. Princeton, Princeton University Press.

- (1995). 'Unwritten Teachings in the Parmenides', The Review of Metaphysics 48 (3), pp. 591633.

Nails, Debra (2002). The People of Plato: A Prosopography of Plato and Other Socratics, Indianapolis, Hackett.

Nehamas, Alexander (1998). The Art of Living: Socratic Reflections from Plato to Foucault. Berkeley, University of California Press.

Nussbaum, Martha (1994). The Therapy of Desire: Theory and Practice in Hellenistic Ethics. Princeton, Princeton University Press.

Palmer, John Anderson (1999). Plato's Reception of Parmenides. Oxford, Oxford University Press.

Patterson, Richard (1999). 'Forms, Fallacies, and the Purposes of Plato's Parmenides', Apeiron 32, pp. 55-71.

Peterson, Sandra (2003). 'New Rounds of the Exercise of Plato's Parmenides', The Modern Schoolman 80, pp. 245-275.

Proclus (trans. J. M. Dillon and Glenn R. Morrow) (1987). Proclus' Commentary on Plato's Parmenides. Princeton, Princeton University Press.

Plato (trans. M. L. Gill and Paul Ryan) (1997). Parmenides, Plato: Complete Works. Indianapolis, Hackett.

Rickless, Samuel (2007). Plato's Forms in Transition: A Reading of the Parmenides. Cambridge, Cambridge University Press.

Sayre, Kenneth (1983). Plato's Late Ontology. Princeton, Princeton University Press.

- (1996). Parmenides' Lesson. Notre Dame, University of Notre Dame Press.

- (2005). 'The Method Revisited', Plato's Parmenides: Proceedings of the Fourth Symposium Platonicum Pragense, pp. 165-180.

Scolnicov, Samuel (2005). Plato's Parmenides. Berkeley, University of California Press.

Turnbull, Robert G. (1998). The Parmenides and Plato's Late Philosophy. Toronto, University of Toronto Press. 